\title{
La inocuidad: principio informante y de adecuación de deberes preventivos y buenas prácticas en la atención remota y presencial del consumidor durante el contexto de la pandemia de COVID-19* Safety: Principle in the adequacy of preventive duties and good practices in remote and face-to-face consumer attention during the context of the COVID-19 pandemic
}

\author{
ERIKA ISLER SOTO** \\ Universidad de Talca (Chile)
}

Resumen: Siendo el principio de inocuidad una directriz informante en los estatutos de protección de los consumidores, este texto propone revisar su concretización en los derechos, deberes y buenas prácticas que tienen lugar a propósito de la atención del consumidor en el contexto de la pandemia de COVID-19. Para ello, comienza con una aproximación a la pandemia y sus principales características. Subsecuentemente, aborda el principio de inocuidad en relación a tres aspectos: la integridad personal y patrimonial del consumidor como su fundamento, y sus características principales (concepto indeterminado que da origen a deberes o informa prácticas autónomas e inicialmente preventivas); su ámbito de vigencia en el sistema de consumo chileno; y la noción de consumidor vulnerable como criterio de adecuación. Luego, examina dicha temática tanto de manera general como a propósito de la atención remota y presencial. En ese sentido, este estudio postula que, en todas esas dimensiones, la conducta de proveedores y consumidores debe ajustarse a los imperativos de seguridad que permitan prevenir la generación de un daño para los sujetos intervinientes en la relación de consumo y el resto de la población. Ello se deriva del carácter de orden público que reviste el resguardo de la integridad personal y patrimonial del individuo.

Palabras clave: Consumidor, COVID-19, buenas prácticas, deberes preventivos, responsabilidad civil

Abstract: As the principle of safety is an informing guideline in the Consumer Protection Law, this text reviews its concretization in the rights, duties and good practices that take place with regard to consumer care in the context of

* Este trabajo forma parte del proyecto FONDECYT de Iniciación № 11190230: «Los medios de tutela del consumidor ante el producto defectuoso, en la Ley 19.496", del que la autora es investigadora responsable.

** Profesora de Derecho Civil en la Universidad de Talca. Abogada, licenciada en Ciencias Jurídicas y Sociales por la Universidad Austral de Chile, licenciada en Estética por la Pontificia Universidad Católica de Chile, magíster en Derecho con mención Derecho Privado por la Universidad de Chile, magíster en Ciencia Jurídica por la Pontificia Universidad Católica de Chile, y doctora en Derecho por la Pontificia Universidad Católica de Chile.

Código ORCID: 0000-0002-2545-9331. Correo electrónico: eisler@utalca.cl 
the COVID-19 pandemic. With that objective, it begins with an approach to the pandemic and its main characteristics. Subsequently, the safety principle is explained in relation to three aspects: The consumer's personal and patrimonial integrity, and its main characteristics; its scope in the Chilean consumer protection system; and the notion of vulnerable consumer as an adequacy criterion. This topic is then explained in a general way and with regard to remote and face-to-face market. In that sense, this study postulates that, in all these dimensions, the behavior of suppliers and consumers must be adjusted to the safety imperatives that prevent risk for the consumer and the rest of the country. That is derived from the character of public order that has the protection of the personal and patrimonial integrity of the consumer.

Key words: Consumer, COVID-19, good practices, preventive duties, liability

CONTENIDO: I. INTRODUCCIÓN.- II. ALGUNAS CONSIDERACIONES GENERALES ACERCA DE LA PANDEMIA DE COVID-19.- III. LA SEGURIDAD EN EL CONSUMO: UN PRINCIPIO INFORMANTE.- III.1. LA INTEGRIDAD: EL CONTENIDO DEL DERECHO A LA SEGURIDAD.- III.2. CARACTERÍSTICAS DE LOS DEBERES DE SEGURIDAD.- III.2.1. LOS DEBERES DE SEGURIDAD: INICIALMENTE PREVENTIVOS Y SECUNDARIAMENTE REPARATORIOS.- III.2.2. LA OBLIGACIÓN DE SEGURIDAD EN LA RELACIÓN DE CONSUMO: SIEMPRE UNA OBLIGACIÓN PRINCIPAL Y AUTÓNOMA.- III.3. LA VIGENCIA DE UN PRINCIPIO DE INOCUIDAD EN EL CONSUMO.- III.4. LA ADECUACIÓN DE LA NOCIÓN DE SEGURIDAD EN EL CONSUMO.- III.4.1. UNA NUEVA LECTURA DEL DERECHO A LA SEGURIDAD: LA INOCUIDAD EN TIEMPOS DE PANDEMIA.III.4.2. LA NOCIÓN DE CONSUMIDOR VULNERABLE COMO CRITERIO DE ADECUACIÓN DE LA SEGURIDAD EN EL CONSUMO.- IV. LA ATENCIÓN DEL CONSUMIDOR.- IV.1. ASPECTOS GENERALES.- IV.2. LA ATENCIÓN REMOTA.- IV.2.1. LA ATENCIÓN REMOTA: PREFERENCIA, INCENTIVO Y FORTALECIMIENTO.- IV.2.2. DERECHOS Y DEBERES A PROPÓSITO DE LA ATENCIÓN REMOTA.- IV.3. LA ATENCIÓN PRESENCIAL.- IV.3.1. LAS NORMAS IMPERATIVAS COMO ESTÁNDAR MÍNIMO.- IV.3.2. ALGUNAS PRÁCTICAS EN PARTICULAR.- V. CONCLUSIONES.

\section{INTRODUCCIÓN}

La comunidad nacional e internacional se encuentra a la expectativa del descubrimiento de una vacuna o tratamiento que pueda hacer frente de manera eficaz a la pandemia de COVID-19. Algunos estudios han aventurado que, de no arribarse a tales resultados, los confinamientos y el distanciamiento físico podrían extenderse incluso hasta el año 2022 (Kissler et al., 2020).

En este contexto, Kurz, el canciller austríaco, comenzó a acuñar la expresión «nueva normalidad» (Neue Normalität) ${ }^{1}$ para referirse a

1 Ver Bundeskanzleramt (14 de abril de 2020). 
la forma de vida que se deberá adoptar en el tiempo intermedio. La Organización Mundial de la Salud (OMS), por su parte, lanzó una advertencia similar ${ }^{2}$ e hizo suya la misma expresión (New normal) para recordarnos que el mundo no volverá a ser el de antes («the world will not and cannot go back to the way things were») $)^{3}$, sino que debemos construir uno más seguro, saludable y preparado.

Más allá de las críticas que ha recibido la utilización de dicha fórmula - en Chile fue invocada y luego reemplazada por la de «retorno seguro»-, lo cierto es que la ocurrencia de la pandemia constituye un evento que, aunque forzadamente, nos ha obligado a adoptar nuevas formas de relacionamiento personal y patrimonial y, con ello, nuevas modalidades de contratación.

Por otra parte, no resulta verosímil que los establecimientos comerciales se mantengan inactivos hasta finalizada la emergencia, especialmente si esto último demora en darse un tiempo prolongado. A causa de ello, los derechos y deberes que se derivan de la relación de consumo deben ajustarse en procedencia y contenido a la realidad imperante, por lo que cabe cuestionarse la forma de adecuación de aquellos que efectivamente han sido recogidos por los estatutos de protección de los consumidores, así como la eventual vigencia de los que, no obstante no estar expresamente tipificados, serán igualmente exigibles.

Desde luego, la Ley 19.496 sobre Protección de los Derechos de los Consumidores chilena (LPDC) no se situó en el escenario actual, por lo que omite disposiciones que resuelvan explícitamente la disyuntiva. Sin embargo, sí se refiere a las prestaciones básicas de seguridad, prerrogativas a partir de las cuales podría esbozarse una respuesta en atención a que su ubicación (parte general) insinuaría su carácter de guía para los vínculos jurídicos que se encuentren cubiertos por esta normativa.

La importancia de esta temática es múltiple, alcanzando tanto a la prevención de lesiones de derechos como una eventual responsabilidad reparatoria. En ese sentido, su tratamiento incidirá en la formación y configuración de las matrices de riesgo de las empresas, así como en la fijación de las acciones preventivas, correctivas y de detección que integren sus programas destinados a satisfacer los requerimientos que se derivan del sistema nacional de consumo.

Cabe mencionar que, dado que el análisis de esta temática puede involucrar diversas aristas (productos defectuosos, garantía legal, servicios de transporte, etc.), por razones de extensión, el presente texto

2 Ver World Healthcare Organization (22 de abril de 2020).

3 Ver World Healthcare Organization (22 de abril de 2020).

LA INOCUIDAD;

PRINCIPIO

INFORMANTEY DE

ADECUACIÓN DE

DEBERES

PREVENTIVOS Y

BUENAS PRÁCTICAS

EN LA ATENCIÓN

REMOTAY

PRESENCIAL DEL

CONSUMIDOR

DURANTE EL

CONTEXTO DE

LA PANDEMIA DE

COVID-19

SAFETY: PRINCIPLE

IN THE ADEQUACY

OF PREVENTIVE

DUTIES AND GOOD

PRACTICES IN

REMOTE AND FACE-

TO-FACE CONSUMER

ATTENTION DURING

THE CONTEXT OF

THE COVID-19

PANDEMIC 
se referirá únicamente a la atención del consumidor, con una referencia especial al ordenamiento jurídico chileno.

\section{ALGUNAS CONSIDERACIONES GENERALES ACERCA DE LA PANDEMIA DE COVID-19}

Si bien las pandemias suelen compartir ciertas características, ellas no se identifican plenamente entre sí, por lo que los derechos y obligaciones que jurídicamente surgirán dependerán de cada caso concreto.

Hasta el momento, la información oficial que circula ${ }^{4}$ nos señala que la forma de contagio de la COVID-19 es de persona a persona, principalmente a través de gotículas expedidas de la nariz o boca de un individuo enfermo. Se agrega, asimismo, que es posible adquirir la enfermedad luego de tocar un objeto sobre el cual se depositó el virus y, a continuación, la nariz, la boca o los ojos. Además, existe evidencia de que personas contagiadas, pero asintomáticas, pueden también ser un factor de transmisión.

Por otra parte, las formas de prevención que se han recomendado ${ }^{5}$ $-y$, en algunos casos, además ordenado ${ }^{6}$ - corresponden al lavado frecuente de manos con agua y jabón por un mínimo de veinte segundos; la mantención de distancia mínima de un metro entre individuos; estornudar o toser cubriendo boca y nariz con el antebrazo o con un pañuelo desechable; evitar tocarse los ojos, la nariz o la boca; no compartir bombilla (sorbete), vaso o cubiertos entre personas; y evitar saludar con la mano o darse besos.

Los principales síntomas reconocidos, en tanto $^{7}$, son la fiebre sobre $37,8^{\circ} \mathrm{C}$, tos seca, dificultad para respirar, dolor de garganta, dolor de cabeza y el cansancio, a los cuales se agregan otros menos frecuentes ${ }^{8}$, como dolores y molestias, congestión nasal, conjuntivitis, diarrea, pérdida del gusto o el olfato, y erupciones cutáneas o cambios de color en los dedos de las manos o los pies.

Como se verá más adelante, dichos antecedentes servirán al menos para construir el estándar mínimo conforme al cual deberán fijarse los deberes preventivos y reparatorios que surjan o sean exigibles dentro del marco de la pandemia de COVID-19. Lo anterior se entronca con la incidencia de la previsibilidad de los daños o el riesgo como elemento integrante de la responsabilidad, de tal manera que el surgimiento de nuevos conocimientos científicos por los cuales se amplíe, reafirme

4 Ver Organización Mundial de la Salud (2020b) y Gobierno de Chile (2020).

5 Al respecto, ver Gobierno de Chile (2020) y Organización Mundial de la salud (2020a).

6 Por ejemplo, se dispone el uso obligatorio de mascarillas en ciertos lugares. Ver RE 282 (17 de abril de 2020).

7 Ver Gobierno de Chile (2020)

8 Ver Organización Mundial de la Salud (2020b). 
o incluso se rebata tal información, repercutirá necesariamente en la dinámica del vínculo de consumo.

Cabe señalar, asimismo, que se mencionan como grupos de riesgo a las personas mayores y enfermos crónicos, quienes en el derecho de consumo suelen ser calificados como consumidores vulnerables (hipervulnerables). La advertencia de que ciertos grupos de individuos pueden verse particularmente afectados por la enfermedad SARS-CoV-2 implica que, en el desarrollo de una relación de consumo - cualquiera sea su naturaleza-, se deban elevar los estándares de seguridad esperable, de tal manera que accedan al vínculo jurídico en condiciones de inocuidad aceptable según los imperativos sociales. Se volverá sobre esto más adelante.

\section{LA SEGURIDAD EN EL CONSUMO: UN PRINCIPIO INFORMANTE}

La protección integral del consumidor no solo involucra aspectos de carácter patrimonial, sino también extrapatrimoniales, dentro de los cuales se encuentra el reguardo de la integridad. Este último, al vincularse con bienes jurídicos no disponibles, no solo debe gozar de mecanismos de protección más eficaces, sino que también debe alcanzar todas las instituciones y reglas del derecho de consumo. En ese sentido, se trataría de un principio general informante, lo cual cobra especial relevancia en tiempos de emergencia.

III.1. La integridad: el contenido del derecho a la seguridad El derecho a la seguridad en el consumo tiene por objeto resguardar ya no la sola expectativa que el consumidor se hubiere formado legítimamente respecto de la calidad de la prestación, sino su propia integridad, por lo que se trata de una garantía de carácter extrapatrimonial (Fernández Fredes, 1997, p. 41).

Su contenido en tanto, se encamina a una tutela personal y patrimonial (Borda, 2014, pp. 52-53; Ruiz-Tagle, 2010, p. 336; Zentner, 2017, p. 305)9. Así, Cabanillas Sánchez (2000) explica que:

Mientras los deberes de prestación (principales o accesorios) tratan de proteger el interés del acreedor en el cumplimiento de la prestación, los llamados deberes de protección, tratan de evitar al acreedor daños que puedan producirse, con ocasión de la relación obligatoria, en otros bienes del mismo (p. 266).

9 Tal es el propósito de los deberes de seguridad (Cabanillas Sánchez, 2000, p. 265). El deber de seguridad es equivalente al deber de protección (p. 267).

LA INOCUIDAD:

PRINCIPIO

INFORMANTEY DE

ADECUACIÓN DE

DEBERES

PREVENTIVOSY

BUENAS PRÁCTICAS

EN LA ATENCIÓN

REMOTAY

PRESENCIAL DEL

CONSUMIDOR

DURANTE EL

CONTEXTO DE

LA PANDEMIA DE

COVID-19

SAFETY: PRINCIPLE

INTHE ADEQUACY

OF PREVENTIVE

DUTIES AND GOOD

PRACTICES IN

REMOTE AND FACE-

TO-FACE CONSUMER

ATTENTION DURING

THE CONTEXT OF

THE COVID-19

PANDEMIC 
En aplicación de lo anterior, los estatutos reguladores de la relación de consumo, al establecer los mecanismos de tutela de un consumidor lesionado o expuesto a un daño derivado de un producto, distinguen entre las anomalías de conformidad (inaptitud) y las de seguridad. En efecto, en atención a que la calidad puede ser renunciada (LPDC, art. 14; CC, art. 12), pero no la seguridad (LPDC, art. 3, letra d), es que el primer supuesto es abordado desde la responsabilidad reparatoria, en tanto que respecto del segundo se agrega la preventiva.

Por otra parte, cabe considerar que la pandemia puede comprometer no solo la integridad física del consumidor, sino que también la psicológica. Dicha apreciación ha sido recogida por el Servicio Nacional del Consumidor (Sernac) (RE 360, 20 de abril de 2020), motivándolo a emitir, en ejercicio de sus funciones (LPDC, art. 58, letra b), algunas circulares interpretativas de la LPDC, aplicables al ofrecimiento de bienes o servicios en medio de la emergencia. Se pueden citar así las que se refieren a buenas prácticas (RE 360, 20 de abril de 2020), seguridad en el consumo y el resguardo de la salud de los consumidores (RE 371, 23 de abril de 2020), y plazos de garantías legales y convencionales (RE $\mathrm{N}^{\circ} 340,9$ de abril de 2020).

\section{III.2.Buenas prácticas, deberes y obligaciones: la atribución de los costos y la asunción de responsabilidad}

La seguridad en el consumo puede ser resguardada por la vía de diversos mecanismos de tutela plasmados en obligaciones jurídicas propiamente tales, o bien en otros instrumentos de menor coercitividad como la autorregulación, los códigos de conducta y las buenas prácticas. La importancia de calificar una práctica como integrante de alguna de las categorías indicadas radica en que ello repercutirá en los efectos jurídicos que se derivan de su incumplimiento, así como en la determinación del sujeto que debe asumir sus costos.

Así, la satisfacción de un deber de seguridad contemplado en la propia LPDC, o bien en su normativa complementaria, debe ser asumida patrimonialmente por su legitimado pasivo; esto es, normalmente el proveedor, sin perjuicio de los deberes de cuidado puestos de cargo del consumidor en el artículo 3 de la LPDC. En este caso, se trata de conductas que deben imperativamente ser satisfechas, sin que el obligado pueda sustraerse de ellas mediante un juicio de costo-beneficio. Lo anterior se sustenta en el carácter de orden público de la integridad que busca tutelar.

También es posible que los mecanismos de prevención se encuentren contenidos en la autorregulación, en ocasiones codificada bajo la forma de «códigos de conducta» (por ejemplo, el Código Chileno de Ética Publicitaria). Si ellos, además pueden enmarcarse dentro de la 
normativa estatal, se seguirán las reglas señaladas en el supuesto anterior, tanto en lo que dice relación con la atribución de responsabilidad como en la asunción de costos. Por el contrario, si se trata de conductas que exceden el estándar impuesto por el legislador, serán exigibles en principio únicamente respecto de aquellas instituciones, sujetos y empresas que voluntariamente se hubieren adscrito al sistema de autorregulación, quienes, por consiguiente, deberán asumir el costo que su implementación implique. En caso contrario, se expondrán a ser sancionados por el correspondiente órgano fiscalizador que se hubiere instituido para tal efecto.

Así:

la autorregulación [...] representa, por un lado, una elaboración normativa $[\ldots]$ y, por otro, una capacidad volitiva de los sujetos que participan del sistema. De hecho, estos últimos se comprometen, de manera voluntaria, a observar sus preceptos y las sanciones que se apliquen, por parte del ente encargado de su observancia —organismo de control—, en caso de incumplimiento por el proveedor (López Jiménez \& Redchuk, 2015, p. 69).

Respecto del resto de los proveedores, esta servirá de propuesta de modelo ético, a la manera del soft law o las denominadas «buenas prácticas empresariales».

Estas últimas en general suelen ir más allá de las exigencias normativas, pudiendo plasmarse en corpus codificados, planes propios de prevención o incluso en sugerencias de la autoridad (por ejemplo, circulares del Sernac). Las prácticas en este caso no resultan exigibles al proveedor en principio, por lo que no se encuentra obligado a asumir los costos de su implementación, aunque su verificación otorga un indicio de civilidad. Así explica Cañizares Arévalo (2020): «las empresas socialmente responsables reconocen la influencia que ejercen en su entorno social conformado por su grupo de interés y los efectos que de sus actividades se derivan» (p. 108). Asimismo, contribuyen a la mantención de la fidelidad de la clientela. En este sentido, López Jiménez y Redchuck (2015, p. 69) estiman que las buenas prácticas amplían la protección del consumidor, lo que incrementa la confianza de este último en el proveedor.

Por otra parte, los instrumentos voluntarios en ocasiones explicitan prácticas usuales de la industria o acuerdos ya alcanzados (López Alfonsín, 2004, p. 159), por lo que es posible que con el tiempo adquieran una mayor fuerza coercitiva formal si se los incorpora en normas derivadas del Poder Legislativo o Ejecutivo que consagren deberes específicos de conducta. En la misma línea, la redacción y configuración de mecanismos voluntarios de prevención no libera al legislador de

LA INOCUIDAD:

PRINCIPIO

INFORMANTEY DE

ADECUACIÓN DE

DEBERES

PREVENTIVOSY

BUENAS PRÁCTICAS

EN LA ATENCIÓN

REMOTAY

PRESENCIAL DEL

CONSUMIDOR

DURANTE EL

CONTEXTO DE

LA PANDEMIA DE

COVID-19

SAFETY: PRINCIPLE

IN THE ADEQUACY

OF PREVENTIVE

DUTIES AND GOOD

PRACTICES IN

REMOTE AND FACE-

TO-FACE CONSUMER

ATTENTION DURING

THE CONTEXT OF

THE COVID-19

PANDEMIC 
cumplir con su cometido de otorgar soluciones integrales y eficientes a los problemas jurídicos que se presentan en la práctica (López Jiménez \& Redchuk, 2015, p. 68).

Finalmente, cabe recordar que una vez entrada en vigencia la Ley 21.081, constituye una circunstancia atenuante de la responsabilidad infraccional en el derecho de consumo chileno:

la colaboración sustancial que el infractor haya prestado al Sernac antes o durante el procedimiento sancionatorio administrativo o aquella que hubiere prestado en el procedimiento judicial, la cual se configurará si el proveedor cuenta con un plan de cumplimiento en las materias a que se refiere la infracción respectiva, que haya sido previamente aprobado por el Servicio y se acredite su efectiva implementación y seguimiento (LPDC, art. 24, inc. 4, letra c).

\section{III.3. Características de los deberes de seguridad}

Constituyendo el resguardo de la seguridad en el consumo, la justificación precisa del surgimiento de imperativos originalmente no explicitados por la ley o la convención al momento de la aparición de una emergencia sirve también de criterio fundamental para delimitar su origen y contenido. A continuación, se revisarán algunas de sus características.

\section{III.3.1. Los deberes de seguridad: inicialmente preventivos y secundaria- mente reparatorios}

El carácter de orden público de los bienes jurídicos comprometidos en la seguridad en el consumo implica que los deberes que encuentran su fundamento en ella sean principalmente preventivos, pues el sujeto pasivo se encontrará así obligado a evitar riesgos que pudieran comprometer la salud o integridad del consumidor.

La indemnización, por lo tanto, procederá de manera secundaria; esto es, cuando los mecanismos destinados a la evitación de los daños no hayan sido eficaces y, al mismo tiempo, se cumpliesen los presupuestos de la responsabilidad reparatoria. La instauración de deberes preventivos de seguridad busca entonces evitar la producción de daños, a diferencia de la responsabilidad civil (Parra Lucán, 2015, p. 150); en ese sentido, la reparación será un efecto que ni el proveedor ni el consumidor querrán inicialmente que se produzca. Por tal razón, no resultaría aceptable que un proveedor deje de implementar medidas adecuadas destinadas a prevenir daños en virtud de un cálculo por el cual el pago de eventuales multas e indemnizaciones — costo-beneficio- pudiese resultar menos gravoso desde el punto de vista económico. 
Si bien una conducta como la anterior puede encontrar algún sustento en un examen de eficiencia, atenta gravemente contra los principios de nuestra sociedad, según los cuales los bienes jurídicos no disponibles, como la vida y la integridad, gozan de una tutela preferente. Para evitar una inescrupulosa ponderación en tal sentido, los legisladores pueden recurrir a la responsabilidad sancionatoria y -aunque discutiblemente- a los daños punitivos ${ }^{10}$. Sobre este punto, cabe destacar que en Chile, luego de la entrada en vigencia de la Ley 21.081, la LPDC instituye como circunstancia agravante el «[haber] dañado la integridad física o psíquica de los consumidores o, en forma grave, su dignidad» (art. 24, inc. 5, letra c); y «[haber] puesto en riesgo la seguridad de los consumidores o de la comunidad, aun no habiéndose causado daño» (art. 24, inc. 5, letra d). Asimismo, se faculta al tribunal a incrementar en un $25 \%$ el monto de la indemnización en el mismo supuesto descrito (LPDC, arts. 53 C y 24, inc. 5; Mendoza Alonzo, 2019, p. 67).

\section{III.3.2.La obligación de seguridad en la relación de consumo: siempre una obligación principal y autónoma}

Sibien se ha calificado a los deberes de seguridad como anejos (Cabanillas Sánchez, 2000, p. 263) al interés fundamental del acreedor (interés en la prestación), estos no le serán accesorios. En efecto, la jerarquía que les otorga su objeto de resguardo, la integridad, les imprime también un carácter autónomo por el cual operarán con independencia del eventual cumplimiento de la prestación principal. Así, Cabanillas Sánchez (2000) explica que:

Mientras los deberes de prestación (principales o accesorios) tratan de proteger el interés del acreedor en el cumplimiento de la prestación, los llamados deberes de protección, tratan de evitar al acreedor daños que puedan producirse, con ocasión de la relación obligatoria, en otros bienes del mismo (p. 263).

A consecuencia de lo anterior, los deberes preventivos rigen con independencia o incluso en ausencia de la responsabilidad reparatoria. Un ejemplo claro de ello lo encontramos en la vigencia de los imperativos de vigilancia, información y retirada, aun cuando se hubiere extinguido la acción que tiene por objeto resarcir daños derivados de un producto defectuoso. Por tal razón, y en atención a la necesidad de resguardar la integridad del consumidor, el solo transcurso del plazo de prescripción establecido por el ordenamiento jurídico para solicitar la indemnización de los perjuicios sufridos no suprime la obligación del proveedor de

10 De acuerdo a Mendoza Alonzo (2019), el daño punitivo «persigue que el responsable por un daño no sólo repare a la víctima, sino también que el daño no vuelva a ser cometido y que se castigue al responsable por el mismo. Por ende, cumple una función sancionatoria» (p. 74). En ese sentido, «la asemeja (de manera tenue) a la responsabilidad penal, que es la obligación de responder por una infracción cometida y de sufrir la pena prevista por el texto que la reprime» (Le Tourneau, 2004, p. 22).

LA INOCUIDAD:

PRINCIPIO

INFORMANTEY DE

ADECUACIÓN DE

DEBERES

PREVENTIVOS Y

BUENAS PRÁCTICAS

EN LA ATENCIÓN

REMOTAY

PRESENCIAL DEL

CONSUMIDOR

DURANTE EL

CONTEXTO DE

LA PANDEMIA DE

COVID-19

SAFETY: PRINCIPLE

INTHE ADEQUACY

OF PREVENTIVE

DUTIES AND GOOD

PRACTICES IN

REMOTE AND FACE-

TO-FACE CONSUMER

ATTENTION DURING

THE CONTEXT OF

THE COVID-19

PANDEMIC 
emitir una alerta de seguridad si descubre una amenaza no advertida al tiempo de la entrada en circulación del bien. Similar consideración se aplica a los riesgos de desarrollo.

\section{III.3.3. La obligación de seguridad: ¿diligencia o resultado?}

Otra cuestión sobre la que conviene reflexionar guarda relación con la conducta que cabe esperar del deudor para que se entienda cumplida la obligación de seguridad.

En sistemas comparados, se la ha calificado como «de resultado» (Cabanillas Sánchez, 2000, p. 268), por lo que se le reclama «la pretensión misma, sin miramientos a la diligencia que haya comprometido para obtenerla» (Pizarro Wilson, 2008, p. 258). Ello conllevaría a que, en el ámbito en análisis, solo se cumpla con el deber de seguridad en la medida de que exista una ausencia de riesgos, dando cuenta de la sola producción de un daño o de una infracción (Baraona González, 2005, p. 129). En esta vereda, explica Cabanillas Sánchez (2000, p. 269) que el propósito del deber de protección se consigue únicamente si se le atribuye tal carácter. Agrega que no serviría de mucho si fuera de medios, puesto que una calificación en tal sentido únicamente impondría al perjudicado la necesidad de acreditar la negligencia de su contraparte (p. 268).

La Corte de Casación francesa (Recurso 08-10070, 2009) ${ }^{11}$ ha arribado a un resultado similar, aunque a propósito de un contrato de arrendamiento, al fallar que la obligación de seguridad que tiene el arrendador respecto de la arrendataria es de resultado, de tal manera que no bastaría con que el primero acredite diligencia en el actuar para liberarse de pagar los perjuicios causados por la caída originada en un desnivel formado entre la entrada de un ascensor y el piso.

En tanto, conforme a una segunda línea de interpretación, se consideraría a la obligación de seguridad como de medios; esto es, cuando «al deudor se le exige una conducta diligente para que logre la satisfacción de la prestación comprometida» (Pizarro Wilson, 2008, p. 257). En este caso, el ordenamiento no espera una total ausencia de daño, sino únicamente que existan los medios para que no se produzca (Baraona González, 2005, p. 129).

En Chile, la doctrina se ha decantado por esta segunda respuesta al calificar el deber de seguridad propio del vínculo laboral, indicando que la prestación se compondría de una «actividad» o «diligencia» (Baraona González, 2005, p. 132; Sierra H. \& Nasser Olea, 2012, p. 66) ${ }^{12}$. Se niega, por lo tanto, que el empleador deba representarse

11 Audiencia Pública, Recurso 08-10070 (Corte de Casación, Tercera Sala de lo Civil [Francia], 1 de abril de 2009). Recuperado de https://www.legifrance.gouv.fr/affichJuriJudi.do?oldAction=rechJuriJudi\&idT exte=JURITEXT000020483728\&fastReqld $=413535063 \&$ fastPos $=1$

12 Cabe señalar, en todo caso, que el artículo 184 del Código del Trabajo consagra el deber de seguridad en los siguientes términos: «El empleador estará obligado a tomar todas las medidas necesarias 
anticipadamente todos los riesgos a los cuales podrían verse sometidos los trabajadores (Gajardo Harboe, 2014, p. 22) y evitarlos, puesto que ello sería imposible en una sociedad precisamente denominada como «de riesgos» (Baraona González, 2005, p. 132; Lanata Fuenzalida, 2019, p. 6; Sierra H. \& Nasser Olea, 2012, pp. 66-67). Como contrapartida, este podría liberarse de responsabilidad si acredita que ha cumplido de buena fe con otorgar eficazmente seguridad a sus trabajadores (Sierra H. $\&$ Nasser Olea, 2012, p. 66).

Por su parte, Barrientos Zamorano (2012, pp. 82, 87) agrega que el imperativo de seguridad opera en la fase anterior a la producción del daño desde dos dimensiones. En primer lugar, pone al empleador en la necesidad de prever y representarse los posibles riesgos que pueden acaecer en el marco del vínculo laboral. A lo anterior, sigue la prevención; es decir, la implementación de mecanismos que eviten el riesgo en la medida en que ello sea posible (Barrientos Zamorano, 2012, p. 82; Gajardo Harboe, 2014, p. 22).

En el ámbito del derecho de consumo, el artículo 47 de la LPDC, a propósito de los productos inseguros, prescribe que se podrán eximir de responsabilidad aquellos proveedores que suministren bienes o presten servicios observando el cumplimiento de medidas legales o reglamentarias y de los demás cuidados y diligencias que procedan, según su naturaleza. Dicha regla insinúa, al menos en una primera lectura, la posibilidad de que ciertos daños no sean resarcibles si se hubiere actuado en el marco de ciertos estándares exigibles.

No obstante, la LPDC no señala en términos generales si el deber de seguridad (art. 3, letra d) tiene un carácter absoluto o relativo, ni tampoco explicita un eventual carácter objetivo o subjetivo de la responsabilidad a partir del cual aventurar si, para el cumplimiento del imperativo en análisis, se requiere la ausencia de una lesión («de resultado») o si bastaría con la actuación conforme a la diligencia esperable («de medios»).

Con todo, la triada previsión-prevención-reparación propuesta por la literatura nacional a propósito del contrato de trabajo permite aventurar que la seguridad será exigible en la medida en que el riesgo pueda ser razonablemente representado por parte del proveedor. Ello implica que una amenaza que provenga de un caso fortuito o fuerza mayor debe ser soportada inicialmente por el consumidor, toda vez que el hecho lesivo sea realmente imprevisible, irresistible y exterior. Asimismo, en esta ponderación se debe tomar en consideración el contexto del contrato de

LA INOCUIDAD:

PRINCIPIO

INFORMANTEY DE

ADECUACIÓN DE

DEBERES

PREVENTIVOSY

BUENAS PRÁCTICAS

EN LA ATENCIÓN

REMOTAY

PRESENCIAL DEL

CONSUMIDOR

DURANTE EL

CONTEXTO DE

LA PANDEMIA DE

COVID-19

SAFETY: PRINCIPLE

IN THE ADEQUACY

OF PREVENTIVE

DUTIES AND GOOD

PRACTICES IN

REMOTE AND FACE-

TO-FACE CONSUMER

ATTENTION DURING

THE CONTEXT OF

THE COVID-19

PANDEMIC 
consumo; esto es, las asimetrías que distancian a las partes del vínculo jurídico y el deber de profesionalidad con el que se espera que actúe el proveedor (LPDC, art. 1, N², 23 y 24). De esta manera, el daño no será reprochable únicamente cuando se haya producido a pesar de una prevención razonable, proporcional y adecuada, conforme al estándar jurídicamente exigible, el cual — como ya se dijo— se eleva cuando se lo examina respecto del proveedor. Así, el ordenamiento jurídico reclama una vez más que la atención del consumidor, presencial o remota, tenga lugar en un marco de inocuidad (art. 3, letra d).

Con todo, en este punto cabe destacar la siguiente consideración de la Corte de Apelaciones de Temuco, emitida a propósito del hurto de dinero que sufrió un consumidor dentro de las instalaciones de un banco:

el fundamento de existencia de la legislación que brinda protección a los derechos de los consumidores la encontramos en el hecho de que la relación entre consumidor y proveedor es asimétrica, razón por la cual esta legislación especial establece un sinnúmero de obligaciones para los proveedores que tienen por objeto emparejar esa brecha y se puedan establecer relaciones de consumo en un plano de igualdad [...]. La empresa querellada y demandada civilmente es efectivamente experta o profesional en el área de las actividades de su giro, por lo que se encuentran en inmejorables condiciones para tomar los resguardos que eviten los menoscabos que la negligente administración o nula preocupación de sus dependientes puedan ocasionar en la prestación de los servicios que configuran su oferta, tanto principal como accesoria, entre los cuales sin duda se cuenta la seguridad (Vergara Arias vs. Banco Santander Chile S.A., 2017) ${ }^{13}$.

Como se puede apreciar, en esta ocasión se reconoce un factor locativo como elemento de atribución de la responsabilidad.

Con todo, lo anterior no obsta a la aplicación de los criterios de determinación de la relación causal. Por otra parte, como ya se señaló, la inocuidad esperable por el ordenamiento jurídico no es absoluta, dependiendo el estándar de lo que la conciencia social proponga.

\section{III.4. La vigencia de un principio de inocuidad en el consumo}

La instauración de mecanismos de seguridad destinados a la prevención de daños implica que se incorpore en el sistema de consumo un principio de inocuidad (De León Arce, 2002, pp. 2182-2183).

En esa línea, legislaciones foráneas han explicitado la imperiosidad de que solo se otorguen prestaciones de consumo seguras. La Directiva

13 Vergara Arias vs. Banco Santander Chile S.A. (C. Ap. de Temuco [Chile], 13 de febrero de 2017). 
Europea 2001/95/CE sobre la seguridad general de los productos prescribe que «Los productores tienen la obligación de poner en el mercado únicamente productos seguros» (art. 3.1), regla que es reiterada también en los ordenamientos internos. Así, en España, el artículo 11 del Texto Refundido de la Ley General para la Defensa de los Consumidores y Usuarios (Real Decreto Legislativo 1/2007) instituye un deber general de seguridad por el cual solo pueden introducirse al mercado productos y servicios seguros (art. 11.1.); esto es, aquellos que:

en condiciones de uso normales o razonablemente previsibles, incluida su duración, no presenten riesgo alguno para la salud o seguridad de las personas, o únicamente los riesgos mínimos compatibles con el uso del bien o servicio y considerados admisibles dentro de un nivel elevado de protección de la salud y seguridad de las personas (art. 11.2).

Similar prescripción encontramos en la normativa sobre seguridad de productos (Real Decreto 1801/2003, art. 4.1) y en la autonómica (Estatuto de las personas consumidoras de Extremadura, art. 8.1).

Si bien el ordenamiento jurídico chileno no contempla una regla explícita en tal sentido, es posible extraerla igualmente de la conjunción entre los derechos básicos a la seguridad en el consumo, la protección de la salud y el medio ambiente (LPDC, art. 3, letra d), y a la indemnización adecuada y oportuna de los perjuicios antijurídicamente sufridos (art. 3 , letra e). Dicha garantía, entonces, unida a la exigencia de profesionalidad con la que se espera actúe el proveedor en sus relaciones con los consumidores (arts. 1, $\mathrm{N}^{\circ} 2 ; 23$ y 24), le impone a este la obligación de tomar las medidas que resulten necesarias para que la integridad de su contraparte no se vea lesionada, de acuerdo al estándar socialmente aceptable. Asimismo, la ubicación que encuentra su consagración (parte general) insinuaría su carácter de guía para los vínculos jurídicos que se encuentren cubiertos por esta normativa.

Por otra parte, precisamente a propósito de la emergencia sanitaria derivada de la COVID-19, el Sernac ha sostenido correctamente que la salud del consumidor debe gozar de la más alta protección, dentro de los intereses y derechos resguardados por el legislador en materia de consumo (RE 371, 23 de abril de 2020).

Ahora bien, el artículo 3, letra d, de la LPDC reconoce la garantía a «[la] seguridad en el consumo de bienes o servicios, la protección de la salud y el medio ambiente y el deber de evitar los riesgos que puedan afectarles». Como se puede apreciar, la fórmula escogida por el legislador es binaria, en el sentido de que pone de cargo tanto del proveedor como del consumidor la consecución de un mercado libre -0 , al menos, reducido a lo socialmente aceptable - de riesgos. De ello se deriva que las nuevas formas de relacionamiento que el coronavirus obligará 
a configurar y mantener en la fabricación, comercialización y disfrute de prestaciones de consumo implicarán el surgimiento de deberes tanto para el prestador como para el destinatario final de bienes o servicios. No obstante, como se señalará, las diligencias esperables de unos y otros serán diversas.

Con todo, cabe prevenir que un adecuado resguardo del consumidor en este aspecto podrá colisionar con el eventual carácter meramente programático que se ha atribuido a los derechos reconocidos en la primera parte del artículo 3 de la LPDC $^{14}$. La urgencia de la pandemia, por lo tanto, podría constituir una excelente oportunidad para dilucidar la disyuntiva.

\section{III.5. La adecuación de la noción de seguridad en el consumo}

Dado que los estatutos de protección al consumidor son regidos por un principio general de inocuidad, corresponde determinar su alcance. El legislador nacional, salvo ciertas obligaciones y deberes especialmente tipificados ${ }^{15}$, no otorga una norma general que determine el contenido del derecho a la seguridad. Se trata, por lo tanto, de un concepto válvula —la «seguridad legítimamente esperable»—, cuya determinación concreta corresponderá al intérprete de acuerdo a las circunstancias que acompañan a la relación de consumo; esto es, su contexto.

Ello alcanzará no solo a los estándares genéricos y específicos de conducta, inspirados en el deber general de no dañar (la prevención), sino también a las buenas prácticas empresariales que, si bien no son exigibles jurídicamente, demostrarán con su implementación el compromiso del proveedor con la protección del consumidor.

\section{III.5.1. Una nueva lectura del derecho a la seguridad: la inocuidad en tiempos de pandemia}

Una resignificación de la seguridad a la luz del mundo pospandemia afectará tanto a la prevención como a la reparación a que pueda dar lugar la LPDC. En ese sentido, incidirá también en la conformación de las matrices de riesgo, particularmente si se considera que es posible que una situación como la que vivimos actualmente puede volverse a repetir ${ }^{16}$. Proveedores $-\mathrm{y}$ consumidores - deberán estar

14 Se discute acerca de si los derechos básicos consagrados en el artículo 3 de la LPDC pueden dar origen a derechos subjetivos o si, más bien, tienen un carácter meramente programático. Al respecto, se puede revisar Acedo Penco (2003, pp. 345-350), Álvarez Moreno (2015, p. 4), Barrientos Zamorano (2013, p. 10), Contardo González (2013, p. 119), Corral Talciani (2013b, p. 109), Espada Mallorquín (2013, p. 136), Faúndez Vergara (2018, p. 83), Isler Soto (2019b, pp. 244-247), Reich (1999, p. 16) y Stiglitz (1997, p. 12).

15 Se puede encontrar un interesante análisis acerca de los deberes genéricos y los deberes específicos en Papayannis (2020, pp. 9-38)

16 Recordemos que Stephen Hawking ya aseveraba en el año 2001 que un virus y no una bomba atómica podría ser la causa de la extinción de la humanidad en la Tierra. Al respecto, ver Highfield (2001). 
entonces preparados para ello, a la vez que una eventual alegación de imprevisibilidad e irresistibilidad de una emergencia derivada de un virus podría perder sustento. De la misma manera, resulta esperable que sea tomada en consideración al momento de establecer las acciones preventivas, correctivas y de detección que integren sus programas destinados a respetar el ordenamiento jurídico vigente ${ }^{17}$.

Si bien después se analizarán las exigencias de seguridad en particular, es preciso adelantar algunos criterios generales. En el caso de Chile cabe recordar, en primer lugar, las directrices formuladas por el Sernac, ya aludidas en referencia al respeto de la seguridad en el consumo ante eventos excepcionales y de pandemia ${ }^{18}$.

Por otra parte, la dignidad humana y las consideraciones bioéticas también emergen como un principio general que debe ser tomado en consideración al momento de implementar cualquier medida de solución que aborde una crisis, tal como lo ha enunciado la Corte Interamericana de Derechos Humanos (9 de abril de 2020) ${ }^{19}$ a propósito de la pandemia.

Asimismo, la adecuación de los deberes y el surgimiento de otros originalmente no contemplados podrá realizarse a partir de la vigencia de los principios de solidaridad (Benedetti, 2020, pp. 268, 273; Federico, 2020, p. 238) y buena fe (Domínguez Guillén, 2020, pp. 380-381; Federico, 2020, p. 238). A propósito del cumplimiento de las obligaciones, cobrará relevancia el principio de conservación del contrato (Federico, 2020, p. 241), poniendo de cargo del proveedor la resistencia de la convención, aun cuando ello le genere un costo económico mayor, siempre y cuando sea razonable. Con todo, uno de los criterios más importantes a ser tomados en consideración al determinar la prestación esperable o recomendable guarda relación con el destinatario final del bien o servicio.

17 Esta consideración resulta especialmente relevante si se recuerda que la LPDC, luego de la entrada en vigencia de la Ley 21.081, contempla como una circunstancia atenuante de la responsabilidad infraccional: «La colaboración sustancial que el infractor haya prestado al Servicio Nacional del Consumidor antes o durante el procedimiento sancionatorio administrativo o aquella que haya prestado en el procedimiento judicial. Se entenderá que existe colaboración sustancial si el proveedor contare con un plan de cumplimiento específico en las materias a que se refiere la infracción respectiva, que haya sido previamente aprobado por el Servicio y se acredite su efectiva implementación y seguimiento» (art. 24, inc. 4, letra c).

18 Circular interpretativa sobre buenas prácticas de los proveedores frente a la pandemia provocada por el Coronavirus (Covid-19) (RE 360, 20 de abril de 2020); Circular interpretativa sobre resguardo de la salud de los consumidores y de medidas alternativas de cumplimiento, suspensión y extinción de las prestaciones, frente a la pandemia provocada por Coronavirus (COVID-19) (RE 371, 23 de abril de 2020); y Circular interpretativa sobre suspensión de plazos de las garantías legales, voluntarias y de satisfacción durante la crisis sanitaria derivada de Covid-19 (RE №340, 9 de abril de 2020).

19 Sobre tal propuesta: «la referencia a los principios de la bioética, como se sabe: autonomía, justicia, beneficencia y no maleficencia, se interpreta en un sentido argumentativo totalizador, es decir, que no excluye las otras formas de abordajes bioéticos posteriores que los complementan, tales como el método casuístico, el giro empírico y, más recientemente, el giro narrativo» (Juan, 2020, p. 46). Acerca de las libertades religiosas como límite a las medidas de emergencia decretadas con ocasión de la pandemia, ver Paúl Díaz (2020, pp. V-VII).

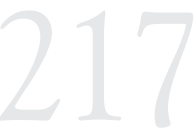

LA INOCUIDAD:

PRINCIPIO

INFORMANTEY DE

ADECUACIÓN DE

DEBERES

PREVENTIVOSY

BUENAS PRÁCTICAS

EN LA ATENCIÓN

REMOTAY

PRESENCIAL DEL

CONSUMIDOR

DURANTE EL

CONTEXTO DE

LA PANDEMIA DE

COVID-19

SAFETY: PRINCIPLE IN THE ADEQUACY

OF PREVENTIVE

DUTIES AND GOOD

PRACTICES IN

REMOTE AND FACE-

TO-FACE CONSUMER

ATTENTION DURING

THE CONTEXT OF

THE COVID-19

PANDEMIC 


\section{III.5.2.La noción de consumidor vulnerable como criterio de adecuación de la seguridad en el consumo}

Al referirse uno de los elementos de adecuación de la seguridad en el consumo (LPDC, art. 3, letra d) a las características del destinatario final del bien o servicio, en el contexto de la pandemia cobra especial relevancia la categoría especial de consumidor vulnerable.

\section{Vulnerabilidad aún en normalidad}

El fundamento de la formulación de reglas especiales para el vínculo de consumo radica en la existencia de diversas asimetrías que suelen distanciar a las partes que en él intervienen. Así, se ha advertido que en la gran mayoría de los casos el consumidor se sitúa en una posición desventajada respecto del proveedor, derivada de la información que tiene a su disposición, la posibilidad de determinar el contenido contractual (poder de negociación) y hacer frente a emergencias, etc. Se presumió entonces que el destinatario final de bienes o servicios era vulnerable respecto de un proveedor profesional.

No obstante, una vez que la tutela del consumidor se encontraba ya asentada, se comenzó a advertir que algunos de ellos podían ubicarse en una situación aún más desmejorada, por lo que los estándares normativos que fijaban los estatutos reguladores de la relación de consumo podían no resultar suficientes para resguardar sus derechos. Surgió entonces la propuesta de reconocer la vulnerabilidad adicional a la que se encontraban sometidos, y se los denominó consumidores vulnerables (hipervulnerables, doblemente vulnerables).

De acuerdo a Hernández Díaz-Ambrona (2016), se trataría de:

todos aquellos consumidores afectados por determinadas circunstancias personales, económicas, culturales o sociales, como pueden ser determinadas enfermedades físicas o mentales, la edad, la falta de experiencia comercial, o simplemente situaciones de necesidad, que dificultan el entendimiento que tendría un consumidor medio, disminuyéndolo, por lo que precisan una especial atención (p. 39).

Álvarez Moreno (2015), en tanto, los circunscribe a los individuos:

afectados por especiales circunstancias personales, económicas, culturales o sociales (como las enfermedades físicas o mentales, edad, falta de experiencia comercial, etc.) que dificultan el entendimiento que tendría un consumidor medio, disminuyéndolo, por lo que precisan una especial atención (p. 31).

La Organización para la Cooperación y el Desarrollo Económicos u OCDE (2007), por su parte, que ya los había reconocido a propósito de 
la resolución de disputas y el derecho a resarcimiento, los concibe como aquellos:

consumidores particulares o categorías de consumidores quienes, debido a características o circunstancias personales (por ejemplo, edad, capacidad física o mental, educación, ingreso, idioma o ubicación remota) pueden tener dificultades particulares en el acceso a la resolución de disputas y el resarcimiento (p. 8).

De lo anterior se puede desprender que el origen de la especial vulnerabilidad puede ser diverso, existiendo para ello varios factores, entre ellos la edad (menores, adultos mayores), la salud (discapacitados, alérgicos a ciertos alimentos), la situación económica y cultural ${ }^{20}$ (inmigrantes), la ubicación geográfica, etc. Sin embargo, no en todos los casos la particularidad generará una desventaja en el ámbito de las relaciones de consumo. Así, por ejemplo, la intolerancia a la lactosa no incidirá en la aptitud de un individuo para celebrar un contrato electrónicamente, pero sí podría determinar la procedencia de deberes de información respecto de productos alimenticios.

Por otra parte, la adscripción a la categoría en comento puede ser también dinámica y modificarse en el tiempo. En esa línea, el menor la abandonará al cumplir 18 años (CC, art. 26), pudiendo retornar a ella si ingresa a la tercera o cuarta edad.

Ahora bien, la determinación de las reglas aplicables a estos individuos, dentro de las cuales se encuentran desde luego las que se refieren a la seguridad, debe encontrarse informada por los principios de inclusión, no discriminación arbitraria y no patologización.

En esa línea, la Convención Interamericana sobre la Protección de los Derechos Humanos de las Personas Mayores establece como directrices informadoras el derecho a la participación, integración e inclusión plena y efectiva de este colectivo dentro de la sociedad (art. 3, letra e). Además, se les reconocen el derecho a la dignidad y a la evitación del aislamiento (art. 6), así como a la independencia y la autonomía (art. 7), los cuales por cierto deben releerse de acuerdo a la emergencia actual.

Asimismo, cabe indicar que similares directrices se han reconocido a propósito de las personas con discapacidad en general (Convención sobre los Derechos de las Personas con discapacidad, arts. 3, letra b, y 5 ; Convención Interamericana para la eliminación de todas las formas de discriminación contra las personas con Discapacidad, art. 2; Ley 20.422,

20 De acuerdo al informe del Observatorio de Conflictividad Civil y Acceso a la Justicia (2018, p. 147), u OCCA, en la esfera de consumo los reclamos de los estratos socioeconómicos más altos se encuentran sobrerrepresentados, mientras que los de los sectores de menores ingresos están subrepresentados.

LA INOCUIDAD:

PRINCIPIO

INFORMANTEY DE

ADECUACIÓN DE

DEBERES

PREVENTIVOSY

BUENAS PRÁCTICAS

EN LA ATENCIÓN

REMOTAY

PRESENCIAL DEL

CONSUMIDOR

DURANTE EL

CONTEXTO DE

LA PANDEMIA DE

COVID-19

SAFETY: PRINCIPLE

IN THE ADEQUACY

OF PREVENTIVE

DUTIES AND GOOD

PRACTICES IN

REMOTE AND FACE-

TO-FACE CONSUMER

ATTENTION DURING

THE CONTEXT OF

THE COVID-19

PANDEMIC 
art. 1) y de los menores que se encuentren en tal condición (Convención sobre los Derechos del Niño, art. 23).

2. La vulnerabilidad ante eventos excepcionales

A propósito de la pandemia, la especial vulnerabilidad cobra una singular relevancia por diversas razones. En primer lugar, porque uno de los índices que deben utilizarse al calificar la gravedad de una pandemia es el impacto (Organización Mundial de la Salud, 2017, p. 8), el cual naturalmente será mayor o menor según las características de la población que se vea expuesta.

Asimismo, si bien los hechos de la naturaleza no pueden evitarse, los desastres sí (San Martín Neira, 2019, p. 1151), precisamente a partir de la reducción de las vulnerabilidades sociales (Ejsmentewicz, 2020, p. 96). En ese sentido, la consideración de San Martín Neira (2020), en orden a sostener que aunque el origen del virus es natural, su propagación depende del hombre, implica que efectivamente el cumplimiento de los deberes preventivos debe ir encaminado a la supresión de aquellos factores — «vulnerabilidades»— que permiten su difusión ${ }^{21}$.

Por tal razón, la adecuación del derecho a la seguridad debe realizarse en función de los individuos que intervendrán en la relación de consumo -nuevamente, «el contexto»—, por lo que la concurrencia de una característica personal por la cual el riesgo del contagio pueda implicar una complicación de la salud especialmente grave —adultos mayores, embarazadas, etc. - ha de ser tomada en consideración al integrar e interpretar las garantías básicas de los consumidores. Lo anterior conlleva a que en el desarrollo de una relación de consumo se deban elevar los estándares de la prestación esperable, de tal manera que dichos individuos puedan intervenir en el vínculo jurídico en condiciones de inocuidad.

En términos generales, dicha prevención ha sido recogida por la misma Corte Interamericana de Derechos Humanos (9 de abril de 2020), la cual ha señalado que la tutela de los derechos en medio de la emergencia debe realizarse con énfasis en los grupos de individuos que pudieran verse afectados de manera más desproporcionada por encontrarse en una situación de mayor vulnerabilidad. Similar reflexión realiza el Sernac a propósito de las relaciones de consumo (RE 371, $\mathrm{N}^{\circ} 1,23$ de abril de 2020).

\section{IV.LA ATENCIÓN DEL CONSUMIDOR}

A partir de la necesidad de resguardar el desarrollo de las diversas relaciones de consumo en un contexto de seguridad, el acaecimiento de

21 El Estado tiene la obligación de reducir la vulnerabilidad y, así, reducir el riesgo de desastre (CPR, art. 1, incs. 4 y 5; Ejsmentewicz, 2020, p. 96). 
la emergencia ha implicado el surgimiento de nuevos derechos y deberes para las partes del vínculo jurídico que se forma entre un proveedor y un consumidor, además de la adecuación de buenas prácticas empresariales. Así, Krieger (2020) explica que:

la forma que se impone para la reconstrucción de la economía es la del restablecimiento del consumo, de modo que la determinación de la supremacía de los intereses de los consumidores por encima de los de los proveedores; no solo tiene un profundo basamento legal, sino que además tiene un marcado beneficio macroeconómico.

Ahora bien, al determinar los deberes que surgen para cada una de las partes de la relación de consumo se debe recordar el rol que los efectos cumplen en la calificación de un hecho como desastre. Como ha explicado San Martín Neira (2020), la ocurrencia de un evento de este tipo puede no ser posible de resistir, pero sí sus consecuencias dañosas — distingue entre ocurrencia y perniciosidad—, de tal manera que la responsabilidad del proveedor surgirá igualmente aun cuando no hubiere tenido parte en el origen del virus, si su incumplimiento de deberes de cuidado facilitó la propagación.

También Ejsmentewicz (2020, p. 97) sostiene que el riesgo ha de ser intervenido para que no se presente en su dimensión bruta, sino solo residual. Aunque el planteamiento se refiere a la responsabilidad del Estado, el ejercicio de ponderación que realiza la autora resulta útil también al momento de revisar la posición jurídica del proveedor:

el caso fortuito en tanto eximente de responsabilidad solo podría configurarse si previamente nos encontramos en escenarios de riesgo residual, es decir, si previamente la autoridad implementó todas las medidas posibles y razonables para reducir el riesgo. A su vez, dichas medidas no sólo deben referirse a la gestión de la emergencia, sino también a acciones de prevención (p. 98).

Con todo, a continuación se propondrán algunas fórmulas de resguardo de la seguridad en el consumo (LPDC, art. 3, letra d), a propósito de la atención del consumidor en el marco de una relación de consumo, distinguiéndose algunas implicancias generales, las prácticas remotas y las presenciales.

\section{IV.1.Aspectos generales}

La atención del consumidor puede presentarse bajo las distintas formas de la relación de consumo, pudiendo así tener lugar en la etapa precontractual o incluso si ninguna convención se llega a celebrar. Es lo que ocurre, por ejemplo, cada vez que se cotiza un producto o servicio, se transita por un local comercial sin que se hubiere aún verificado

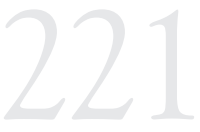

LA INOCUIDAD:

PRINCIPIO

INFORMANTEY DE ADECUACIÓN DE DEBERES

PREVENTIVOSY

BUENAS PRÁCTICAS

EN LA ATENCIÓN

REMOTA Y

PRESENCIAL DEL

CONSUMIDOR

DURANTE EL

CONTEXTO DE

LA PANDEMIA DE

COVID-19

SAFETY: PRINCIPLE IN THE ADEQUACY OF PREVENTIVE

DUTIES AND GOOD

PRACTICES IN

REMOTE AND FACE-

TO-FACE CONSUMER

ATTENTION DURING

THE CONTEXT OF

THE COVID-19

PANDEMIC 
una compraventa («vitrineo»), se visitan páginas web dispuestas por el proveedor para ofrecer alguna prestación, etc.

Nos encontramos entonces frente a un vínculo de carácter extracontractual y, como tal, de discutida circunscripción al régimen de la LPDC chilena, en atención a que alguna doctrina ha exigido la celebración de un contrato de consumo para que el vínculo pueda ser alcanzado por la LPDC (Jara Amigo, 1999, pp. 48 y 51; 2006, pp. 21-58; Ruiz-Tagle Vial, 2010, pp. 303-305). El fundamento de ello se encontraría en las menciones de «acto jurídico oneroso» y cobro de un «precio o tarifa» que el legislador incorpora en las definiciones de consumidor y proveedor (art. $1, \mathrm{~N}^{\circ} 1$ y 2 ), respectivamente.

No obstante, se trata de una propuesta errónea ${ }^{22}$ en el sentido de que la propia LPDC consagra infracciones que se configuran sin convención (arts. 13, 15, 28, 29, etc.). Lo anterior ha sido reconocido, además, en la misma definición de consumidor invocada por la tesis anterior (art. 1, $\mathrm{N}^{\circ} 1$ ) al prescribir que pueden tener tal carácter tanto quienes «adquieran» como aquellos que «utilizan» o «disfrutan» el producto o servicio. Por otra parte, como explica Barrientos Camus (2009, p. 698), la segunda interpretación se sustenta además en la consagración amplia del derecho a resarcimiento (LPDC, art. 3, letra e).

Asimismo, es posible que también la atención se presente una vez que la convención ya se haya perfeccionado, como ocurriría por ejemplo con los servicios de posventa. La discusión acerca de la aplicabilidad de la LPDC a este supuesto persiste, en los términos ya indicados y con las mismas argumentaciones esgrimidas, debido a que las obligaciones principales de las partes — por ejemplo, el pago del precio y la entrega del producto- se encontrarían extinguidas ${ }^{23}$.

En todo caso, cualquiera sea la manifestación concreta del vínculo de consumo, siempre debe encontrarse informada por el principio de inocuidad referido.

Al margen de ello, y respecto de la formulación de la oferta en general, el sistema de libre determinación de precios que rige en Chile en un contexto de normalidad es abandonado cuando se decreta un estado de excepción constitucional. En efecto, en este último escenario ${ }^{24}$ —en el que efectivamente nos encontramos - la normativa nacional sanciona incluso

22 Adhieren la tesis de la relación de consumo: Cárdenas Bustamante (1999, pp. 69-70), Fernández Fredes (1998, pp. 107-12), Hernández Paulsen y Gatica Rodríguez (2019, pp. 23-27), Isler Soto (2010, pp. 97-126), Momberg Uribe (2004, pp. 41-62; 2013a, pp. 3 y ss.; 2013b, pp. 66-76; 2013c, pp. 77-83) y Pinochet Olave (2011, pp. 343-367).

23 Para un análisis más detallado de la responsabilidad poscontractual en el derecho de consumo, ver Farías Soto (2014) e Isler Soto (2019a, pp. 335-382; 2019c, pp. 68-87).

24 Chile se encuentra bajo estado de excepción constitucional de catástrofe por calamidad pública, de acuerdo al Decreto 104 (18 de marzo de 2020), prorrogado por noventa días mediante el Decreto 269 (16 de junio de 2020). 
penalmente la especulación de precios de «alimentos, vestuarios, herramientas, materiales de construcción, productos, medicamentos y artículos farmacéuticos de uso en medicina humana y veterinaria, menaje de casa, combustibles, jabón y bienes que sirvan para el alhajamiento o guarnecimiento de una morada» (Decreto 104 que fija el texto refundido, coordinado y sistematizado del Título 1 de la Ley 16.282, art. 5) ${ }^{25}$.

Además, esta situación podría enmarcarse dentro del estado de necesidad $^{26}$, cuya procedencia como vicio del consentimiento ha sido defendida por algún sector de la doctrina nacional ${ }^{27}$. Asimismo, y como adecuadamente ha relevado el Sernac, se hace necesario mantener el suministro permanente y razonable de bienes y servicios (RE 371, 23 de abril de 2020), toda vez que este tipo de prestaciones permitirán y facilitarán la realización de cuarentenas y confinamientos que son indispensables para prevenir la difusión del virus SARS-CoV-2.

\section{IV.2. La atención remota}

Sin duda, la contratación electrónica se ha consolidado fácticamente como el mecanismo mediante el cual proveedores y consumidores intervienen en el mercado ${ }^{28}$. Pinochet Olave (2005, pp. 55-92) ha explicado que aunque se originó como un fenómeno remoto, ello no necesariamente se mantiene, en el sentido de que actualmente también es preferido por individuos que incluso pueden encontrarse en un mismo lugar. En efecto, aunque se trata de una forma de configuración de la relación de consumo, cuya ocurrencia había venido aumentando progresivamente en los últimos años, es a partir de la aparición del SARS-CoV-2 y, sobre todo, de la mantención voluntaria u obligatoria de confinamientos preventivos, que se afianzó probablemente de manera

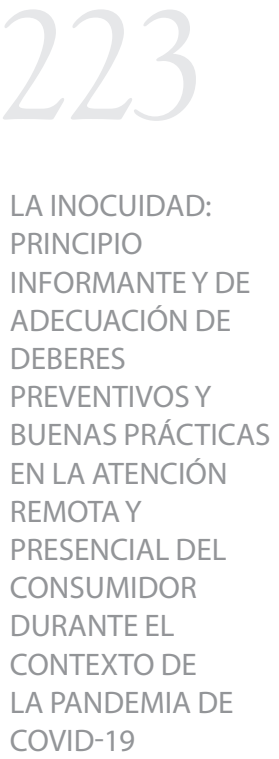

SAFETY: PRINCIPLE INTHE ADEQUACY OF PREVENTIVE DUTIES AND GOOD PRACTICES IN REMOTE AND FACETO-FACE CONSUMER ATTENTION DURING THE CONTEXT OF THE COVID-19 PANDEMIC

25 A lo anterior, se suma la fijación de precios máximos de ciertas prestaciones médicas. Ver RE 215 (30 de marzo de 2020) y RE 258 (15 de abril de 2020).

26 En Francia, se sanciona la obtención de condiciones más beneficiosas de contratación mediante prácticas abusivas. Ver Code Civil (art. 1143).

27 El fundamento principal de la incorporación del estado de necesidad como un supuesto de fuerza radica en la defensa de que esta no solo puede provenir de un acto humano, sino también de circunstancias externas (Ducci Claro, 2005, pp. 273-274). Con todo, el supuesto cuestionado es recogido en la Ley 19.947 de Matrimonio Civil (art. 8, $\mathrm{N}^{\circ} 3$ ) con el objeto de resguardar plenamente e consentimiento libre. Sobre la misma temática, se puede revisar Corral Talciani (2018, pp. 556-557).

$28 \mathrm{Si}$ bien la LPDC reconoce los contratos electrónicos o a distancia, no los define; no obstante, la doctrina ha esbozado algunas definiciones. Así, los primeros han sido concebidos como aquellos en los que «el consentimiento se haya formado por medios electrónicos» (Pinochet Olave, 2006, p. 99). Para los segundos, en tanto, se han postulado dos posibles criterios de delimitación: la reunión de las partes en un mismo lugar, y la posibilidad de que una eventual aceptación sea conocida por el oferente inmediatamente después de ser emitida o no. De acuerdo al primer criterio, «contratos entre presentes son los que se celebran entre personas que se encuentran reunidas en un mismo lugar, entre personas que están una frente a la otra, y contratos entre ausentes los que se celebran entre personas que se encuentra en distintos lugares, una en Santiago, por ejemplo, y la otra en Buenos Aires» (Alessandri Rodríguez et al., 1998b, p. 216). Conforme al segundo, en tanto, los «contratos entre presentes son aquellos en que la aceptación puede ser conocida por la otra parte al tiempo o inmediatamente de ser emitida; y contratos entre ausentes aquellos en que la aceptación puede ser conocida por el oferente sólo después de cierto tiempo, más o menos largo, de ser formulada» (p. 216). 
definitiva como el vehículo en el que se plasmarán la voluntad de las partes de la relación de consumo, en orden a regular sus derechos y deberes y efectuar los intercambios patrimoniales que procedan.

\section{IV.2.1. La atención remota: preferencia, incentivo y fortalecimiento}

Los antecedentes científicos que se conocen sugieren que, probablemente, la forma de relacionamiento jurídico que más propenda a la seguridad en el consumo sea precisamente aquella que tiene lugar sin contacto físico ni abandono del espacio de resguardo, en el sentido de que es la que genera menor riesgo de contagio. Por otra parte, aún en tiempos de normalidad, constituye una herramienta que facilita el acceso al vínculo de consumo a aquellos individuos que pudieran tener dificultades para concurrir a un establecimiento físico, por ejemplo, por presentar una especial vulnerabilidad.

En atención a lo anterior, y sobre todo considerando que probablemente la superación de la emergencia se logre recién después de un tiempo (luego del cual podrían surgir rebrotes o bien otros virus), es que resultaría recomendable que el proveedor incentive este tipo de atención mediante el establecimiento de eficientes, expeditos y asequibles canales remotos. Si lo anterior se realiza adecuadamente, como contrapartida se desincentivará la concurrencia presencial, contribuyendo asimismo a la adopción de prácticas de autocuidado por parte del consumidor, quien, como se señaló, tiene el deber de evitar riesgos (LPDC, art. 3, letra d).

El Instituto de Derecho Europeo también lo ha entendido así, recomendando la contratación y mantención de relaciones jurídicas bajo modalidades a distancia (Principles for the COVID-19 crisis, 2020, principio 10). En el mismo sentido, el Sernac ha explicitado el fortalecimiento de la atención remota de los consumidores como una de las buenas prácticas que deben implementarse frente a una pandemia como la que atravesamos (RE 360, 20 de abril de 2020; RE 371, 23 de abril de 2020). Asimismo, ha instado a los proveedores a informar eficazmente acerca de sus datos de contacto, de tal manera que se propenda a una comunicación fluida con la clientela (RE 360, 20 de abril de 2020, $\mathrm{N}^{\circ} 1.1$ ).

\section{IV.2.2. Derechos y deberes a propósito de la atención remota}

El sistema de consumo ya contemplaba, aún antes de la ocurrencia de la pandemia, reglas aplicables a la forma de interrelación en comento, todas las cuales deben ser respetadas y ponderadas a la luz de la emergencia sanitaria. Por otra parte, recordemos que en la determinación de su contenido ha de tomarse especialmente en cuenta la situación de aquellos consumidores que son considerados como vulnerables (RE 184, 21 de marzo de 2019) — menores, adultos mayores, etc.—, quienes podrían más fácilmente formarse expectativas inexistentes respecto de un bien y sus atributos. 
1. La formación del consentimiento y el perfeccionamiento del contrato

En primer lugar, el proveedor debe poner especial cuidado en resguardar el libre consentimiento del consumidor en orden a obligarse y a elegir la prestación (LPDC, art. 3, letra a), tanto en lo que dice en relación con la mantención de adecuadas y suficientes plataformas digitales o electrónicas mediante las cuales formular la oferta y emitir la eventual aceptación como en la información precontractual que se otorgará al público respecto del perfeccionamiento de la convención. Así, el Sernac, al interpretar la LPDC, ha señalado que en este estadio gobierna un principio de transparencia que conduce a la necesidad de que rija un imperativo de consentimiento informado (RE 184, 21 de marzo de 2019, No 1, letras b y d; RE 326, 6 de abril de 2020, N 3). En aplicación de lo anterior, y aunque la LPDC no prohíbe la manifestación tácita de voluntad - a diferencia del silencio-, el Sernac propone que la forma expresa es aquella que resguarda de mejor manera el derecho a la libre elección del bien o servicio (LPDC, art. 3, letra a), la cual debería requerirse tanto para la celebración como para la modificación y terminación de una convención de consumo (RE 326, 6 de abril de 2020, $\mathrm{N}^{\circ} 1.2$ y 4.3$)$.

En este punto cabe recordar que, de acuerdo a nuestro ordenamiento jurídico, «el consentimiento no se entenderá formado si el consumidor no ha tenido previamente un acceso claro, comprensible e inequívoco de las condiciones generales del mismo y la posibilidad de almacenarlos o imprimirlos» (LPDC, art. 12 A). Asimismo, se prescribe que «la sola visita del sitio de Internet en el cual se ofrece el acceso a determinados servicios, no impone al consumidor obligación alguna, a menos que haya aceptado en forma inequívoca las condiciones ofrecidas por el proveedor» (art. $12 \mathrm{~A})$.

Nuestra institucionalidad, en tanto, ha expresado que se pueden considerar medios idóneos para la celebración o modificación electrónica de un contrato aquellos que permitan autentificar y verificar en forma previa la identidad del consumidor y su efectivo consentimiento (RE 326, 6 de abril de 2020, $\mathrm{N}^{\circ} 4.3$ ).

\section{Los deberes de información}

En segundo término, aquella parte de la relación de consumo que se encuentre en una posición privilegiada en cuanto al conocimiento de las verdaderas características de la prestación — proveedor - debe proporcionar a la otra — consumidor - los antecedentes necesarios para que disminuya la asimetría informativa que los distancia.

Tal es la razón por la cual el ordenamiento jurídico establece deberes de información que pueden proceder en todo el iter contractual — desde la

LA INOCUIDAD:

PRINCIPIO

INFORMANTEY DE

ADECUACIÓN DE

DEBERES

PREVENTIVOSY

BUENAS PRÁCTICAS

EN LA ATENCIÓN

REMOTAY

PRESENCIAL DEL

CONSUMIDOR

DURANTE EL

CONTEXTO DE

LA PANDEMIA DE

COVID-19

SAFETY: PRINCIPLE

INTHE ADEQUACY

OF PREVENTIVE

DUTIES AND GOOD

PRACTICES IN

REMOTE AND FACE-

TO-FACE CONSUMER

ATTENTION DURING

THE CONTEXT OF

THE COVID-19

PANDEMIC 
fase previa a la posterior- o incluso en la dimensión extracontractual, los cuales quedarían cubiertos por la expresión «información básica comercial», definida como «los datos, instructivos, antecedentes o indicaciones que el proveedor debe suministrar obligatoriamente al público consumidor, en cumplimiento de una norma jurídica» (LPDC, art. 1, $\mathrm{N}^{\circ}$ 3). Sobre estos imperativos, señala Barrientos Zamorano (2013): «la información necesaria para los usuarios consiste en darles a estos la seguridad o garantía que necesitan para contrarrestar la distancia y la ausencia de una de las partes en la relación de consumo que está teniendo lugar en internet» (p. 100).

Como se dijo, existen antecedentes que han de ser otorgados en la fase previa al perfeccionamiento del contrato o aun cuando este nunca se celebre. Tal sería el caso, por ejemplo, del procedimiento de celebración de la convención (pasos a seguir), información de contacto del proveedor (RE 326, 6 de abril de 2020, $\mathrm{N}^{\circ} 2.1$ ), características y precio del bien o servicio (LPDC, arts. $1, \mathrm{~N}^{\circ} 3$; y 30), la procedencia del derecho retracto y de servicios de posventa (RE 326, 6 de abril de $2020, N^{\circ} 2.2$ y 2.3).

Rige así plenamente el principio de transparencia (Baraona González, 2019, p. 16), que reclama un estándar prestacional superior al mero otorgamiento de antecedentes. Así, De la Maza Gazmuri y Momberg Uribe (2018) señalan que «el control de transparencia exige más que la sola entrega de información por parte del proveedor, ya que requiere además que tales términos se presenten de una manera clara, comprensible e inequívoca para el usuario medio» (p. 88).

Para Barrientos Camus (2018), en tanto, esta directriz:

si bien parte de algunas reglas de información es más que eso. Se trata de un segundo nivel de protección $[\ldots]$ que intenta asegurar no sólo el adecuado suministro de información al consumidor, sino que además comprensión, concreción y claridad de todas las instituciones relacionadas con el consumo, como ofertas, promociones, publicidad, contratos por adhesión, entre otras (p. 1011).

El Sernac (RE 326, 6 de abril de 2020) se ha pronunciado en el mismo sentido, interpretando que por la transparencia:

se intenta propender a una mayor comprensión, concreción y claridad de todas las instituciones relacionadas con el consumo, como lo son las ofertas, promociones, publicidad, entre otros. Mediante este principio, se pretende que el consumidor promedio tenga las herramientas necesarias para una decisión informada, comprendiendo las condiciones contractuales propuestas $\left(\mathrm{N}^{\circ} 3\right)$.

Con todo, una vez que el contrato celebrado por medios electrónicos o a distancia se ha perfeccionado, «el proveedor estará obligado a enviar 
confirmación escrita del mismo que contenga una copia íntegra, clara y legible del mismo [...] por vía electrónica o por cualquier medio de comunicación que garantice el debido y oportuno conocimiento del consumidor» (LPDC, art. $12 \mathrm{~A}$ ).

\section{Derecho a retracto y garantía legal}

La LPDC consagra un derecho de retracto que puede ser ejercido dentro de los diez días siguientes a la «fecha de recepción del bien o de la celebración del contrato en el caso de servicios» (LPDC, art. 3 bis, letra b), salvo que el oferente no hubiere remitido la ya aludida confirmación de la celebración del contrato, en cuyo caso se extenderá a noventa días.

No obstante, el legislador permite al proveedor liberarse de este deber si hubiere informado previamente su improcedencia (LPDC, art. 3 bis, letra c). Ahora bien, atendida la necesidad ya aludida de fortalecer la atención y contratación remota, la mantención de la vigencia de esta prerrogativa constituiría una buena práctica profesional e indicio de responsabilidad social empresarial.

Con todo, lo anterior se entiende sin perjuicio de la garantía legal que procede cuando se ha configurado alguna de las causales del artículo 20 de la LPDC y que no admite supresión ni limitación alguna por parte del proveedor por tratarse de un derecho mínimo e irrenunciable anticipadamente (art. 4).

4. El resguardo de la integridad patrimonial del consumidor

No solo el libre consentimiento y las expectativas que el consumidor razonablemente se hubiere formado respecto de la prestación merecen una tutela jurídica, sino que también —y más importante aún— su integridad.

En ese sentido, el proveedor en cumplimiento de su deber de profesionalidad (LPDC, arts. 1, No 2; 23 y 24) deberá implementar medidas que permitan hacer frente a eventuales vulneraciones de los sistemas informáticos por los cuales pudiera verse comprometido el patrimonio del consumidor ( $\operatorname{RE} 326,6$ de abril de 2020, $\mathrm{N}^{\circ}$ 6.3), particularmente si se considera que la ausencia de población circulante por los espacios públicos conlleva un probable aumento de los delitos informáticos. Los planes de cumplimiento que cada empresa implemente deberán tomar en consideración, por lo tanto, hechos cuya ocurrencia resultará previsible.

En el mismo sentido, el Sernac ha recomendado que, incluso en condiciones de normalidad, el proveedor informe y adopte todas aquellas medidas técnicas que sean necesarias para garantizar la seguridad, integridad y confidencialidad de las transacciones, medios

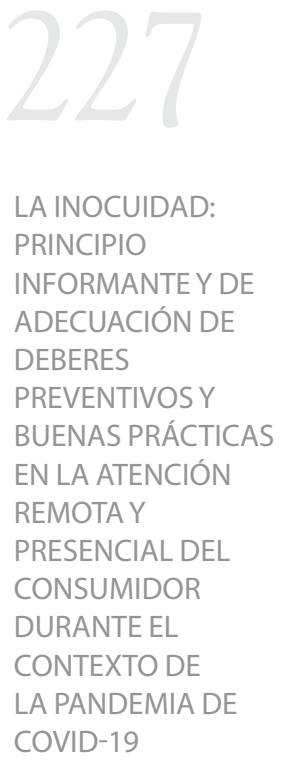

SAFETY: PRINCIPLE INTHE ADEQUACY OF PREVENTIVE DUTIES AND GOOD PRACTICES IN REMOTE AND FACETO-FACE CONSUMER ATTENTION DURING THE CONTEXT OF THE COVID-19 PANDEMIC 
de pago y datos personales de los que sea titular (RE 184, 21 de marzo de 2019, $\mathrm{N}^{\circ}$ 4.7; RE 326, 6 de abril de 2020). Especial cuidado deberá tenerse en aquellos casos en los cuales una oferta pueda ir dirigida a grupos vulnerables, los cuales en ocasiones - pensemos en los adultos mayores- se verán necesariamente enfrentados a la contratación electrónica por primera vez a causa de la pandemia.

\section{IV.3. La contratación y la atención presencial}

Sin perjuicio del auge y consolidación de la contratación a distancia ocurrida a partir de la emergencia sanitaria, lo cierto es que el ofrecimiento de bienes y servicios de manera presencial no desaparecerá y, probablemente, tampoco se postergará hasta que la enfermedad sea totalmente erradicada. Proveedores y consumidores necesariamente deberán entonces ajustarse a una nueva interacción física, en cuyo contexto resulta pertinente preguntarnos por la conducta que cabría esperar de unos y otros en un escenario pospeak de los contagios -0 frente a nuevo brote o surgimiento de otros virus - en el cual se hubiera ya implementado un plan de desconfinamiento.

Examinado el derecho básico a la seguridad en el consumo a la luz del caso concreto planteado, se deduce que una eventual próxima apertura de locales comerciales y su mantención en el tiempo solo podrá ser posible en la medida en que las partes de la relación de consumo adopten las providencias necesarias para que el riesgo para la integridad de la población pueda ser controlado. Siguiendo este razonamiento, surgirán y cobrarán relevancia, por lo tanto, deberes preventivos a ser satisfechos plenamente por todos los intervinientes.

Con todo, aunque no es posible representarnos con certeza el escenario que nos depara la COVID-19, sí se conocen actualmente algunas de sus vías de contagio y la forma en que puede evitarse, como ya se señaló. Analizados dichos antecedentes - y los que vayan surgiendo en el transcurso del tiempo- a la luz del derecho a la seguridad (LPDC, art. 3, letra d), se le podrá dar forma a los deberes, cuya procedencia se defiende.

Algunas de las prácticas que han de implementarse tendrán un carácter general, en tanto que otras podrán depender de la situación fáctica concreta en la que el vínculo se desenvuelva, tales como lugar geográfico (cantidad de contagiados, índice de población de riesgo, densidad habitacional, etc.), público objetivo al cual va dirigida la prestación, horas del día en las que se mantiene abierto el local, etc. Deberán, por lo mismo, adecuarse las matrices de riesgo y los planes de cumplimiento de las empresas también a esta diversa realidad. 
Así, se puede afirmar que una eventual apertura de restaurants, cines, malls y tiendas ha de adaptarse a estos «nuevos tiempos», que probablemente no serán muy breves.

\section{IV.3.1. Las normas imperativas como estándar mínimo}

Desde luego, deben respetarse en primer lugar las medidas obligatorias que el Estado decrete, las cuales, como ha señalado la Corte Interamericana de Derechos Humanos (2020), si pueden:

afectar o restringir el goce y ejercicio de derechos humanos han de ser limitadas temporalmente, legales, ajustadas a los objetivos definidos conforme a criterios científicos, razonables, estrictamente necesarias y proporcionales, y acordes con los demás requisitos desarrollados en el derecho interamericano de los derechos humanos.

Sobre este punto, cabe recordar que Chile se encuentra bajo el estado de excepción constitucional de catástrofe por calamidad pública (Decreto 104, 18 de marzo de 2020; Decreto 269, 16 de junio de 2020), circunstancia que constituye uno de los ejes de las medidas sanitarias, económicas y sociales que se han decretado de manera excepcional a propósito de la pandemia.

En este contexto, y a partir de la necesidad de que la población interactúe aplicando el «distanciamiento físico», es que se ordenó también el respeto de un toque de queda en todo el país, entre las 22:00 y las 05:00 horas del día siguiente. Dicha regla, desde luego, restringe el ofrecimiento de prestaciones vinculadas con la industria de la cultura y el esparcimiento, lo cual se ve reforzado por la suspensión obligatoria de cines, teatros, restaurantes, pubs, discotecas, gimnasio y eventos deportivos (RE 215, 30 de marzo de 2020).

Por otra parte, se decretaron cuarentenas obligatorias bajo un modelo dinámico determinado por un criterio geográfico (RE 208, 25 de marzo de 2020; RE 215, 30 de marzo de 2020) o personal, este último por razón de edad (RE 208, 25 de marzo de 2020; RE 215, 30 de marzo de 2020) ${ }^{29}$ o enfermedad (RE 215, 30 de marzo de 2020), a la vez que se instauraron aduanas y cordones sanitarios (RE 208, 25 de marzo de 2020; RE 215, 30 de marzo de 2020; RE 244, 7 de abril de 2020). Además, se prohibieron las reuniones de más de cincuenta personas (RE 208, 25 de marzo de 2020), así como la visita a establecimientos de larga estadía de adultos mayores ${ }^{30}$ (RE 208, 25 de marzo de 2020; RE 215, 30 de marzo de 2020).

29 Se puede encontrar una crítica a las restricciones de circulación a personas mayores de 70 años en Argentina en Juan (2020, pp. 46-48).

30 El Reglamento de establecimientos de larga estadía para adultos mayores (Eleam) los define como aquellos establecimientos «en que residen personas de 60 años o más que, por motivos biológicos, psicológicos o sociales, requieren de un medio ambiente protegido y cuidados diferenciados que allí

LA INOCUIDAD:

PRINCIPIO

INFORMANTEY DE

ADECUACIÓN DE

DEBERES

PREVENTIVOS Y

BUENAS PRÁCTICAS

EN LA ATENCIÓN

REMOTAY

PRESENCIAL DEL

CONSUMIDOR

DURANTE EL

CONTEXTO DE

LA PANDEMIA DE

COVID-19

SAFETY: PRINCIPLE

IN THE ADEQUACY

OF PREVENTIVE

DUTIES AND GOOD

PRACTICES IN

REMOTE AND FACE-

TO-FACE CONSUMER

ATTENTION DURING

THE CONTEXT OF

THE COVID-19

PANDEMIC 
Naturalmente, dichas prescripciones han de ser satisfechas plenamente por parte de proveedores y consumidores, quienes además deberán —en la medida de lo posible - elevar su diligencia al máximo nivel al momento del cumplimiento. En efecto, la naturaleza no disponible que revisten los bienes jurídicos que buscan ser resguardados por las prácticas imperativas aludidas, y sobre todo las graves consecuencias que pudieren derivarse de su vulneración, implican que rija también a este respecto un principio de máxima buena fe.

No obstante, el pleno respeto del artículo 3, letra d, de la LPDC no se agota en el cumplimiento de medidas imperativas, pudiendo resultar procedentes también otras adicionales. En ese sentido, tanto las prescripciones de la LPDC como aquellas que se derivan de la legislación de emergencia constituyen un piso mínimo sobre el cual resulta esperable que proveedores y consumidores actúen mediante la implementación de medidas adicionales de prevención en atención a que, como se ha venido señalando, los bienes jurídicos que se encuentran en juego son de difícil —en ocasiones imposible - reparación una vez que se han afectado. Sobre este punto, puede resultar útil recurrir a las reflexiones que la doctrina ha formulado acerca de la posibilidad de que pueda surgir responsabilidad, aun en cumplimiento de reglamentos ${ }^{31}$.

En ese sentido, y dependiendo de cómo se vaya desarrollando la emergencia, es plausible, por lo tanto, que nazcan para el proveedor deberes que no cuentan con una tipificación normativa expresa, pero que pueden encontrar fundamento en la diligencia con la que se espera actúe, derivada de su profesionalidad (LPDC, arts. $1, \mathrm{~N}^{\circ} 2 ; 23$ y 24 ), asî como de la ubérrima buena fe con la que debe resguardarse la integridad de los consumidores. Adicionalmente, las directrices propias de la responsabilidad empresarial sugerirán que, en la medida de lo posible, custodie la integridad del consumidor y, con ello, de la población en general.

\section{IV.3.2. Algunas prácticas en particular}

A continuación se revisarán algunas situaciones en particular que pueden presentarse en el marco de la atención al consumidor.

reciben. Dichos cuidados tienen por objeto la prevención y mantención de su salud, la mantención y estimulación de su funcionalidad y el reforzamiento de sus capacidades remanentes» (art. 2).

31 El solo cumplimiento de medidas y reglas fijadas por un reglamento o la ley no importa la automática exención de responsabilidad del proveedor, si se produjere algún daño. Así, tanto la doctrina nacional como la historia fidedigna de la LPDC sugiere que aquellas pueden constituir un indicio de diligencia (Segundo Informe de la Comisión Economía sobre el proyecto de ley 19.496, Senado, 22 de agosto de 1995, Boletín 446-03; Alessandri Rodríguez, 1943, p. 180; Barros Bourie, 2007, pp. 101-103; Corral Talciani, 2010) y de previsibilidad de eventuales efectos lesivos (Contreras Chaimovich, 2015, p. 277). Lo propio también se ha pregonado respecto de la responsabilidad por productos (LPDC, art. 47) en Barros Bourie (2007, p. 758), Corral Talciani (1999, p. 188), Corral Talciani (2013, p. 937) y Fernández Fredes (1997, p. 122). 
1. El acceso a las dependencias del proveedor

El artículo 3, letra c, de la LPDC consagra el derecho básico del consumidor a la no discriminación arbitraria, una de cuyas manifestaciones se traduce no solo en no impedir el acceso del público a las dependencias del proveedor, sino también en facilitarlo cuando el consumidor se encontrase aquejado por alguna circunstancia que se lo dificulte. Lo interesante es que la noción de consumidor vulnerable cobra relevancia no solo al requerir prácticas, dispositivos y medidas que permitan a los individuos afectados por una particular característica (por ejemplo, discapacitados o adultos mayores) acceder al consumo, sino que, además, en el contexto de la pandemia, será el fundamento para restringirlo o bien adecuarlo.

Así, por ejemplo, las personas mayores de 75 años se encuentran sometidas a una cuarentena preventiva obligatoria, por lo que no deberían concurrir a un local comercial (RE 208, 25 de marzo de 2020; RE 215, 30 de marzo de 2020). Por otra parte, y atendido a que estadísticamente el SARS-CoV-2 puede generar consecuencias más gravosas para un cierto grupo de individuos de mayor riesgo, es que resultaría pertinente el establecimiento de horarios exclusivos de atención para ellos, tal como lo ha recomendado nuestra institucionalidad (RE 360, 20 de abril de 2020, $\left.\mathrm{N}^{\circ} 1.3\right)$. Se trataría, esta última, de una práctica discriminatoria, pero justificada.

De la misma manera, en el acceso al consumo, cabe exigir al consumidor que cumpla con los deberes imperativos que ha dispuesto la autoridad; esto es, el uso obligatorio de mascarilla en ciertos lugares de acceso público (RE 282, 17 de abril de 2020; RE 244, 7 de abril de 2020), tales como el transporte público o privado; establecimientos educativos; aeropuertos y terrapuertos; teatros, cines, discotecas, casinos y recintos análogos; supermercados, centros comerciales, hoteles, farmacias y otros lugares de libre acceso; establecimientos de salud; lugares donde se procesen, manipulen o depositen productos, medicamentos o alimentos; lugares de trabajo; recintos deportivos; pubs, restaurantes y cafeterías.

Con fundamento en la misma emergencia, resultaría pertinente también la instauración de aforos máximos, o bien el otorgamiento de la posibilidad de agendar previamente, mediante dispositivos electrónicos, visitas programadas a un local comercial (RE 360, 20 de abril de 2020, $\mathrm{N}^{\circ} 1.3$ ). En España, la autoridad, a modo de buena práctica, ha recomendado que el proveedor procure que el consumidor permanezca en las dependencias únicamente el tiempo necesario para realizar la compra o la operación correspondiente (Secretaría de Estado de Comercio del Ministerio de Industria, Comercio y Turismo, 2020).

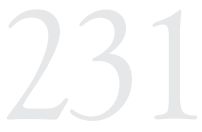

LA INOCUIDAD:

PRINCIPIO

INFORMANTEY DE

ADECUACIÓN DE

DEBERES

PREVENTIVOSY

BUENAS PRÁCTICAS

EN LA ATENCIÓN

REMOTAY

PRESENCIAL DEL

CONSUMIDOR

DURANTE EL

CONTEXTO DE

LA PANDEMIA DE

COVID-19

SAFETY: PRINCIPLE

IN THE ADEQUACY

OF PREVENTIVE

DUTIES AND GOOD

PRACTICES IN

REMOTE AND FACE-

TO-FACE CONSUMER

ATTENTION DURING

THE CONTEXT OF

THE COVID-19

PANDEMIC 
Cabe recordar, finalmente, que cuando se necesite la obtención de un permiso temporal para la realización de compras de insumos básicos (comunas con cuarentena), los guardias de seguridad de supermercados, farmacias u otras instituciones que cuenten con certificación del OS-10 de Carabineros de Chile se encuentran actualmente facultados para solicitar el permiso correspondiente a cualquier persona que tenga intención de ingresar al local comercial. Dicha regla se agregó luego de advertirse que un número considerable de consumidores concurría a realizar compras sin haber realizado el trámite, conducta que, desde luego, transgrede el propio deber de evitar riesgos consagrado en el artículo 3, letra d, de la LPDC.

\section{El espacio físico}

Respecto del espacio físico dentro del cual se desarrolla la relación de consumo, resulta pertinente y recomendable que el proveedor adopte medidas que sean útiles para evitar posibles contagios.

Así, el Sernac adecuadamente propuso la verificación de una disposición y distribución de espacios y mobiliarios que faciliten el libre y expedito tránsito de los clientes (RE 360, 20 de abril de 2020); la evitación del contacto físico entre funcionarios y consumidores (por ejemplo, a través de pantallas), y de aglomeraciones (RE 371, 23 de abril de 2020); la capacitación de los dependientes del local en lo referente a medidas de higiene y seguridad (RE 360, 20 de abril de 2020); y, desde luego, la redacción de un protocolo que se aplique cuando alguno de ellos se contagie (RE 360, 20 de abril de 2020).

La misma consideración había ya enunciado el servicio a propósito de los supermercados y almacenes antes de la pandemia, aunque en el contexto actual cobran una especial relevancia, dado que integran la cadena de distribución de bienes y servicios:

las dependencias del supermercado forman parte de la prestación del servicio, sirven de sustento a la relación de consumo, facilitando el acceso a los servicios ofrecidos y a la adquisición de los productos que se ofrecen, por lo que, si no se toman las medidas necesarias para que dichas dependencias importen un cuidado para los bienes de los consumidores y un desplazamiento sin riesgos para la integridad física de los clientes que ingresan, se estará prestando un servicio de manera negligente, poniendo así en peligro la integridad física de los consumidores (RE 185, 21 de marzo de 2019).

Cabe recordar, asimismo, que al revestir la seguridad en el consumo el carácter de básico, serán titulares del derecho a la seguridad tanto quien ha contratado con el proveedor como quien es parte de una relación de consumo de naturaleza extracontractual. 
Será también adecuado implementar medidas de higiene, entre ellas sanitizar con cierta frecuencia y con productos químicos los espacios físicos de atención; contar con dispensadores de alcohol en gel a la entrada del local ${ }^{32}$, en su interior y en la caja de pago; si es posible - queda dentro del campo de las buenas prácticas, al menos por ahora-, poner a disposición del público, mascarillas y guantes (RE 360, 20 de abril de 2020, $\left.\mathrm{N}^{\circ} 1.4\right)^{33}$; modificar mecanismos de apertura de refrigeradores y estanterías, de tal manera que se puedan recoger los productos en ellos dispuestos sin necesidad de utilizar las manos; instalar separaciones entre el consumidor y el dependiente; y procurar que se mantenga el espacio físico entre consumidores, por ejemplo, con la marcación de lugares de espera, etc.

En España, la autoridad, a modo de buenas prácticas, ha agregado también las siguientes conductas (Secretaría de Estado de Comercio del Ministerio de Industria, Comercio y Turismo, 2020): implementar sistemas de trabajo de turnos que minimicen riesgos sin variar la atención; la limpieza, desinfección y ventilación de locales, máquinas dispensadoras, puestos de trabajo, uniformes y, en general, de cualquier superficie que pueda haber sido tocada luego de cada turno o jornada, según corresponda; la revisión de sanitarios y servicios de aseo; la suspensión del uso del mecanismo biométrico con base en la huella dactilar como forma de control de asistencia; la mantención de distancia mínima; evitar la manipulación directa de productos por parte de consumidores, minimizando sistemas de autoservicio; etc.

De igual forma, y atendido el esquema de la sociedad de consumo, se debe subrayar que un foco importante de contagio puede encontrarse en la circulación de dinero en efectivo. Por tal razón, y aunque no puede prohibirse su utilización como medio de pago, convendría fomentar el uso de tarjetas o dispositivos electrónicos (RE 360, 20 de abril de 2020, $\left.\mathrm{N}^{\circ} 1\right)^{34}$. Cabe señalar, además, que en la práctica algunas instituciones financieras se han apresurado a implementar formas de pago mediante teléfonos celulares o muñequeras electrónicas.

\section{El otorgamiento de información}

Una de las herramientas más eficaces de control de las emergencias sanitarias guarda relación con la educación de la ciudadanía, en el sentido de que esta le permite adquirir los conocimientos necesarios para

32 RE 360 (20 de abril de 2020). Similar recomendación se ha propuesto en España como una buena práctica, como señala la Secretaría de Estado de Comercio del Ministerio de Industria, Comercio y Turismo (2020).

33 Similar recomendación se encuentra en Secretaría de Estado de Comercio del Ministerio de Industria, Comercio y Turismo (2020).

34 Así, se ha recomendado como buena práctica tanto en Chile como en España. Al respecto, ver RE 360 (20 de abril de $2020, N^{\circ} 1.3$ y 1.4) y Secretaría de Estado de Comercio del Ministerio de Industria, Comercio y Turismo (2020).

LA INOCUIDAD:

PRINCIPIO

INFORMANTEY DE

ADECUACIÓN DE

DEBERES

PREVENTIVOS Y

BUENAS PRÁCTICAS

EN LA ATENCIÓN

REMOTAY

PRESENCIAL DEL

CONSUMIDOR

DURANTE EL

CONTEXTO DE

LA PANDEMIA DE

COVID-19

SAFETY:PRINCIPLE

INTHE ADEQUACY

OF PREVENTIVE

DUTIES AND GOOD

PRACTICES IN

REMOTE AND FACE-

TO-FACE CONSUMER

ATTENTION DURING

THE CONTEXT OF

THE COVID-19

PANDEMIC 
implementar medidas de autocuidado, lo que puede alcanzar también el cumplimiento del deber de evitar riesgos (LPDC, art. 3, letra d).

Asimismo, recordemos que la LPDC consagra un derecho a la educación en el consumo (art. 3, letra f), cuya efectiva satisfacción, como explica Bru (2004, p. 21), constituye un mecanismo de tutela preventivo con la importancia que ello reviste en una emergencia sanitaria. Si bien el Estado constituye el primer obligado a propender a su consecución (Espada Mallorquín, 2013, p. 134; Echeverri Salazar \& Ospina Gómez, 2018, p. 190; Fernández Fredes, 1998, p. 118; Organización para la Cooperación y el Desarrollo Económicos, 1999, p. 9; CPR, arts. 1 y 19, $\left.\mathrm{N}^{\circ} 10\right)$, el proveedor no debería restarse de ello.

Por tal razón, en el marco de la atención presencial, resultaría útil que se incorporase advertencias y letreros en los locales comerciales que recuerden las prácticas imperativas estatales, además de otras recomendaciones que puedan contribuir a la prevención del contagio. En su redacción y configuración, también debería tomarse en consideración la capacidad de comprensión del mensaje que un consumidor medio y uno vulnerable pudieran tener.

En España, la autoridad estatal ha recomendado que se informe a consumidores y trabajadores acerca de los procedimientos de higiene decretados por la autoridad sanitaria (Secretaría de Estado de Comercio del Ministerio de Industria, Comercio y Turismo, 2020). En Chile, en tanto, el Sernac también se ha decantado por una propuesta similar:

sea que se trate de medidas establecidas por el proveedor $\mathrm{u}$ otras dispuestas obligatoriamente por la autoridad sanitaria competente, deberán ser informadas a los consumidores de forma previa por todos los medios y canales disponibles haciendo distinción respecto de su obligatoriedad y resguardando siempre la información y dignidad en el trato a los consumidores (RE 360, 20 de abril de 2020, $\mathrm{N}^{\circ} 1.4$ ).

\section{Los deberes del consumidor}

El consumidor no puede transformarse en un agente pasivo en la prevención, sino que se espera de él también una conducta responsable y proactiva en orden a evitar el riesgo de su propio contagio, así como de la propagación del virus a otros sectores de la población, tanto a partir de su deber de evitar riesgos (LPDC, art. 3, letra d) como de la responsabilidad social a la que se encuentra afecto por el solo hecho de vivir en sociedad.

En ese sentido, no solo debe respetar estrictamente una eventual cuarentena a la cual se encontrase obligado, sino que también ha de adoptar las prácticas necesarias para resguardar su salud y la de los demás, siempre que estén a su alcance y de acuerdo a su propia realidad. 
Como se señaló, será distinta la situación de un individuo sin ningún tipo de vulnerabilidad adicional de la de aquel otro que pudiera verse afectado por una circunstancia especial.

Por lo mismo, el consumidor deberá, por ejemplo, utilizar máscaras de protección, evitar tocar productos más allá de lo necesario —si su realidad lo permite, con guantes-, limpiarse las manos antes de ingresar a un local, no concurrir al comercio físico si presenta síntomas de COVID-19, mantener la distancia recomendada por los expertos, etc.

Con todo, la diligencia esperada de proveedores y consumidores deberá fijarse atendiendo a las diversas asimetrías que los distancia, entre ellas la capacidad económica, el acceso a la información, el poder de negociación, etc.

\section{CONCLUSIONES}

De las anteriores reflexiones se puede colegir que en los estatutos de protección al consumidor rige un principio general de inocuidad que debe informar los derechos y deberes derivados de una relación de consumo, la configuración e implementación de buenas prácticas empresariales y, en fin, todas las instituciones del derecho de consumo. En Chile, su vigencia se puede desprender del derecho básico a la seguridad (LPDC, art. 3, letra d), consagrado en la parte general de la Ley 19.496 sobre Protección de los Derechos de los Consumidores.

Por otra parte, los deberes que se derivan de la garantía señalada son siempre principales y preventivos; esto es, tienen por objeto evitar la producción de un daño o su agravamiento. Ello se justifica en el carácter de orden público que revisten los bienes jurídicos protegidos.

Con todo, el derecho a la seguridad en el consumo constituye un concepto válvula (indeterminado) cuyo contenido debe ser adecuado a una situación concreta por el intérprete. En ese sentido, la aparición y desarrollo del SARS-CoV-2, por lo tanto, conllevarán a una nueva lectura de los derechos y deberes contemplados expresamente en los estatutos de protección al consumidor, así como al surgimiento de nuevos derechos y deberes tanto en la atención remota como en la presencial; no obstante, se deberá incentivar la primera modalidad.

Finalmente, cabe señalar que si bien el escenario sanitario actual implica el surgimiento de deberes de prevención tanto para el proveedor como el consumidor, la diligencia esperada se eleva respecto del profesional, atendiendo a su posición de privilegio en la relación de consumo.

LA INOCUIDAD:

PRINCIPIO

INFORMANTEY DE

ADECUACIÓN DE

DEBERES

PREVENTIVOSY

BUENAS PRÁCTICAS

EN LA ATENCIÓN

REMOTAY

PRESENCIAL DEL

CONSUMIDOR

DURANTE EL

CONTEXTO DE

LA PANDEMIA DE

COVID-19

SAFETY: PRINCIPLE

IN THE ADEQUACY

OF PREVENTIVE

DUTIES AND GOOD

PRACTICES IN

REMOTE AND FACE-

TO-FACE CONSUMER

ATTENTION DURING

THE CONTEXT OF

THE COVID-19

PANDEMIC 


\section{REFERENCIAS}

Acedo Penco, Á. (2003). Los derechos básicos de los consumidores reconocidos en el Art. 51 de la Constitución y su ulterior desarrollo mediante el estatuto de los consumidores de Extremadura. Anuario de la Facultad de Derecho, (21), 339-354.

Alessandri Rodríguez, A. (1943). La responsabilidad extracontractual en el Derecho Civil Chileno. Santiago de Chile: Imprenta Universitaria.

Alessandri Rodríguez, A., Somarriva Undurraga, M., \& Vodanovic H., A. (1998). Tratado de Derecho Civil (vol. 2). Santiago de Chile: Editorial Jurídica de Chile.

Álvarez Moreno, M. (2015). La protección jurídica del consumidor en la contratación en general (normas imperativas y pactos al respecto). Madrid: Reus.

Baraona González, J. (2005). La culpa de la víctima en los accidentes del trabajo: dogmática y jurisprudencia chilenas. En J. Baraona González y P. Zelaya Etchegaray (coords.), La responsabilidad por accidentes del trabajo (pp. 123-153). Santiago de Chile: Universidad de los Andes.

Baraona González, J. (2019). Concepto, autonomía y principios del Derecho de Consumo. En M. Morales Ortiz (dir.) y P. Mendoza Alonzo (coord.), Derecho del consumo: ley, doctrina y jurisprudencia (pp. 1-24). Santiago de Chile: Der Ediciones.

Barrientos Camus, F. (2009). ¿Por qué no hay demandas de responsabilidad civil contra el fabricante? En Estudios de Derecho Civil (vol. V). Santiago de Chile: LegalPublishing.

Barrientos Camus, F. (2018). Repensando el control de forma de los contratos por adhesión: una mirada a su aplicación actual y la introducción de la transparencia. En C. Bahamondes Oyarzún, L. Etcheberry Court y C. Pizarro Wilson (eds.), Estudios de Derecho Civil (vol. XIII). Santiago de Chile: Thomson Reuters.

Barrientos Zamorano, M. (2012). La obligación de seguridad en la subcontratación laboral: previsibilidad del hecho y del daño. Revista Chilena de Derecho, 39(1), 77111. https://doi.org/10.4067/s0718-34372012000100005

Barrientos Zamorano, M. (2013). Art. 3 letra b). En I. De la Maza y C. Pizarro Wilson (eds.), La protección de los derechos de los consumidores (pp. 94-103). Santiago de Chile: Thomson Reuters.

Barros Bourie, E. (2007). Tratado de responsabilidad extracontractual. Santiago de Chile: Editorial Jurídica de Chile.

Benedetti, A. (2020). Obbligazioni e contratti al tempo dell'emergenza: l'esperienza italiana (art. 3, comma 6-bis, d.l. n. 6/2020). Actualidad Jurídica Iberoamericana, (12 bis), 266-273.

Borda, A. (2010). La teoría de los actos propios. Un análisis desde la doctrina argentina. En H. Corral Talciani (ed.), Venire contra factum proprium. Escritos sobre la fundamentación, alcance y límites de la doctrina de los actos propios. Santiago de Chile: Universidad de los Andes. 
Bru, J. (2004). Educación y formación del consumidor (reflexiones sobre la conciencia del consumidor. En G. Stiglitz (dir.), Manual de Defensa del Consumidor (pp. 19-52). Rosario: Juris.

Bundeskanzleramt. (14 de abril de 2020). Wir können daher wie geplant heute den ersten Schritt in Richtung neue Normalität setzen. Recuperado de https://www.bundeskanzleramt.gv.at/bundeskanzleramt/nachrichten-derbundesregierung/2020/bundeskanzler-kurz-wir-sind-auf-kurs.html

Cabanillas Sánchez, A. (2000). Los deberes de protección del deudor en el Derecho Civil, en el Mercantil y en el Laboral. Madrid: Civitas.

Cañizares Arévalo, J. (2020). El rol de la responsabilidad social empresarial para las microempresas: iqué tanto se cumplen las buenas prácticas? Aibi Revista de Investigación, Administración e Ingeniería, 8(1), 107-115. https://doi. org/10.15649/2346030x.700

Cárdenas Bustamante, M. (1999). Análisis jurídico de la Ley de Protección al Consumidor. Revista de Derecho Universidad Austral de Chile, X, 69-74.

Contreras Chaimovich, L. (2015). La responsabilidad penal del fabricante por la infracción de sus deberes de vigilancia, advertencia y retirada. Revista Política Criminal, 10(19), 266-296. https://doi.org/10.4067/s0718-33992015000100009

Contardo González, J. (2013). Artículo $3^{\circ}$ E) LPDC. En I. De la Maza y C. Pizarro Wilson (eds.), La protección de los derechos de los consumidores (pp. 117-132). Santiago de Chile: Thomson Reuters.

Corral Talciani, H. (1999). Ley de protección al consumidor y responsabilidad civil por productos y servicios defectuosos. En H. Corral Talciani (ed.), Derecho del Consumo y protección al consumidor: estudios sobre la Ley $N^{\circ} 19.496$ y las principales tendencias extranjeras. Cuadernos de Extensión (pp. 163-211). Santiago de Chile: Universidad de los Andes.

Corral Talciani, H. (2010). Responsabilidad civil en la construcción de viviendas. Reflexiones sobre los regímenes legales aplicables a los daños provocados por el terremoto del 27 de febrero de 2010. Revista Chilena de Derecho, 37(3), 459-475. Recuperado de https://scielo.conicyt.cl/scielo. php? script $=$ sci_arttext\&pid $=$ S0718-34372010000300003

Corral Talciani, H. (2013a). Artículo 47 LPDC. En I. De la Maza y C. Pizarro Wilson (eds.), La protección de los derechos de los consumidores (pp. 933-938). Santiago de Chile: Thomson Reuters.

Corral Talciani, H. (2013b). Artículo 3 letra d). En I. De la Maza y C. Pizarro Wilson (eds.), La protección de los derechos de los consumidores (pp. 109-116). Santiago de Chile: Thomson Reuters.

Corral Talciani, H. (2018). Curso de Derecho Civil. Parte general. Santiago de Chile: Thomson Reuters.

Corte Interamericana de Derechos Humanos (9 de abril de 2020). Declaración de la Corte Interamericana de Derechos Humanos. COVID-19 y derechos humanos: los problemas y desafios deben ser abordados con perspectiva de Derechos Humanos

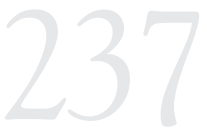

LA INOCUIDAD:

PRINCIPIO

INFORMANTEY DE ADECUACIÓN DE

DEBERES

PREVENTIVOSY

BUENAS PRÁCTICAS

EN LA ATENCIÓN

REMOTAY

PRESENCIAL DEL

CONSUMIDOR

DURANTE EL

CONTEXTO DE

LA PANDEMIA DE

COVID-19

SAFETY: PRINCIPLE

IN THE ADEQUACY

OF PREVENTIVE

DUTIES AND GOOD

PRACTICES IN

REMOTE AND FACE-

TO-FACE CONSUMER

ATTENTION DURING

THE CONTEXT OF

THE COVID-19

PANDEMIC 
y respetando las obligaciones internacionales. Recuperado de https://www.corteidh. or.cr/tablas/alerta/comunicado/declaracion_1_20_ESP.pdf

De la Maza Gazmuri, I., \& Momberg Uribe, R. (2018). La transparencia como mecanismo de tutela de la privacidad de los consumidores y usuarios en contratos electrónicos. Revista Chilena de Derecho y Tecnología, 7(2), 81-111. https://doi. org/10.5354/0719-2584.2018.48812

De León Arce, A. (2002). Nuevos alimentos y OMG: derechos y obligaciones de los consumidores. En Estudios Jurídicos en homenaje al profesor Luis Díez-Picazo (vol. 2). Madrid: Thomson Civitas.

Domínguez Guillén, M. (2020). Pandemia: al rescate de la buena fe en el cumplimiento de las obligaciones. Actualidad Jurídica Iberoamericana, (12 bis), 378-385.

Ducci Claro, C. (2005). Derecho civil. Parte general. Santiago de Chile: Editorial Jurídica de Chile.

Echeverri Salazar, M., \& Ospina Gómez, J. (2018). Obsolescencia programada y derechos del consumidor. En E. Llamas Pombo (coord.), Congreso Internacional de Derecho Civil Octavo Centenario de la Universidad de Salamanca (pp. 179-192). Valencia: Tirant lo Blanch.

Ejsmentewicz, D. (2020). Riesgo residual y caso fortuito. Análisis de la acción pública ante la amenaza del covid-19. En C. Lepin Molina (ed.), Caso fortuito o fuerza mayor en el Derecho. Estudios a partir de la pandemia del Covid-19 (pp. 95-98). Valencia: Tirant lo Blanch.

Espada Mallorquín, S. (2013). Artículo 3 letra f). En I. De la Maza y C. Pizarro Wilson (eds.), La protección de los derechos de los consumidores (pp. 133-139). Santiago de Chile: Thomson Reuters.

European Law Institute (ELI). (2020). Principles for the COVID-19 crisis. Recuperado de https://www.europeanlawinstitute.eu/fileadmin/user_upload/p eli/Publications/ELI_Principles_for_the_COVID_19_Crisis.pdf (consultado el 12 de octubre de $20 \overline{2} 0$ ).

Farías Soto, J. (2014). Breves notas sobre la responsabilidad postcontractual en Chile, particularmente en materia de consumo (en prensa). Recuperado de https:// www.academia.edu/18797322/Breves_Notas_sobre_la_Responsabilidad_ Postcontractual_en_Chile_particularmente_en_materia_de_Consumo (consultado el 30 de julio de 2020).

Faúndez Vergara, J. (2018). El derecho a una información veraz y oportuna en la protección de los consumidores. En H. Carrasco Blanc (ed.), Estudios de Derecho del Consumidor (pp. 75-85). Santiago: Rubicón.

Federico, A. (2020). Misure di contenimento della pandemia e rapporti contrattuali. Actualidad Jurídica Iberoamericana, (12 bis), 236-249.

Fernández Fredes, F. (1998). Nueva Ley del Consumidor: innovaciones y limitaciones. Revista Perspectivas en Política, Economía y Gestión, 1(2), 107-126. 
Fernández Fredes, F. (1997). La protección jurídica de la calidad. En C. Pizarro Wilson (ed.), Temas de Derecho del Consumidor. Cuadernos de análisis jurídico (pp. 106-126). Santiago de Chile: Ediciones Universidad Diego Portales, Servicio Nacional del Consumidor.

Gajardo Harboe, M. (2014). El deber de seguridad. Revista Chilena de Derecho del Trabajo y de la Seguridad Social, 5(9), 15-32. https://doi.org/10.5354/0719. 7551.2014 .42637

Gobierno de Chile. (2020). Plan de Acción Coronavirus COVID-19. Recuperado de https://www.gob.cl/coronavirus/

Hernández Díaz-Ambrona, M. (2016). Consumidor y comerciante. En S. Díaz Alabart (coord.), Manual de Derecho de Consumo (pp. 29-41). Madrid: Reus.

Hernández Paulsen, G., \& Gatica Rodríguez, M. (2019). Protección del consumidor y responsabilidad civil por producto o servicio defectuoso. Revista de Estudios de la Justicia, (31), 17-43.

Highfield. R. (2001). Colonies in space might be only hope, says Hawking. The Telegraph, 16 de octubre. Recuperado de https://www.telegraph.co.uk/news/ uknews/1359562/Colonies-in-space-may-be-only-hope-says-Hawking.html

Isler Soto, E. (2010). La relación de consumo como criterio de aplicabilidad del Derecho de Protección del Consumidor. Revista Derecho de la Empresa, (23), 97 126.

Isler Soto, E. (2019a). Acerca de la responsabilidad civil postcontractual en el derecho del consumidor chileno. Ius et Praxis, 25(1), 335-382. https://doi. org/10.4067/s0718-00122019000100335

Isler Soto, E. (2019b). Derecho de Consumo: nociones fundamentales. Valencia: Tirant lo Blanch.

Isler Soto, E. (2019c). Jurisprudencia de Derecho de Consumo comentada. Santiago de Chile: Rubicón.

Jara Amigo, R. (1999). Ámbito de aplicación de la Ley chilena de protección al consumidor: inclusiones y exclusiones. En H. Corral Talciani (ed.), Derecho del Consumo y protección al consumidor: Estudios sobre la Ley $N^{\circ} 19.496$ y las principales tendencias extranjeras. Cuadernos de Extensión (pp. 47-74). Santiago de Chile: Universidad de los Andes.

Jara Amigo, R. (2006). Ámbito de aplicación de la Ley chilena de protección al consumidor: aplicación de la Ley 19.496 y modificaciones de la Ley 19.955. En Jorge Baraona González y Osvaldo Lagos Villarreal (eds.), La protección de los derechos de los consumidores en Chile: Aspectos sustantivos y procesales luego de la reforma contenida en la Ley 19.955 de 2004. Cuadernos de Extensión Jurídica $N^{\circ} 12$ (pp. 21-58). Santiago de Chile: Universidad de los Andes.

Juan, G. (2020). Coronavirus y paternalismo (in)justificado. Revista Actualidad Jurídica Iberoamericana, (12 bis), 42-51.

LA INOCUIDAD:

PRINCIPIO

INFORMANTEY DE ADECUACIÓN DE

DEBERES

PREVENTIVOSY

BUENAS PRÁCTICAS

EN LA ATENCIÓN

REMOTAY

PRESENCIAL DEL

CONSUMIDOR

DURANTE EL

CONTEXTO DE

LA PANDEMIA DE

COVID-19

SAFETY: PRINCIPLE

IN THE ADEQUACY

OF PREVENTIVE

DUTIES AND GOOD

PRACTICES IN

REMOTE AND FACE-

TO-FACE CONSUMER

ATTENTION DURING

THE CONTEXT OF

THE COVID-19

PANDEMIC 
Kissler, St., Tedijanto, C., Goldstein, E., Grad, Y., \& Lipsitch, M. (2020). Projecting the transmission dynamics of SARS-CoV-2 through the postpandemic period. Science, 368(3493), 860-868. https://doi.org/10.1126/science.abb5793.

Krieger, W. (2020). Las relaciones de consumo después de la pandemia. Herramientas del CCyCN que aportan soluciones al problema. Revista de Derecho del Consumidor, (8). Recuperado de https://ar.ijeditores.com/pop.php?option=ar ticulo\&Hash $=$ f75d8183a4531f99c620bb7dccc9135b (consultado el 15 de abril de 2020).

Lanata Fuenzalida, G. (2019). Responsabilidad contractual y extracontractual por accidentes del trabajo y enfermedades profesionales. Santiago de Chile: Der Ediciones.

Le Tourneau, P. (2004). La responsabilidad civil. Bogotá: Legis.

López Alfonsín, M. (2004). El derecho de los consumidores y el Código de Buenas Prácticas Comerciales: una experiencia novedosa en la Argentina. Foro Jurídico, (3), 157-162.

López Jiménez, D., \& Redchuk, A. (2015). Tendencias sociales en el comercio electrónico de América Latina: a propósito de los proveedores adheridos a códigos de buenas prácticas. Opción, 31 (78), 65-79.

Mendoza Alonzo, P. (2019). Introducción al estatuto de la responsabilidad del proveedor. En M. Morales Ortiz (dir.) y P. Mendoza Alonzo (coord.), Derecho del consumo: ley, doctrina y jurisprudencia. Santiago de Chile: Der Ediciones.

Momberg Uribe, R. (2004). Ámbito de Aplicación de la Ley No 19.496 sobre Protección de los Derechos de los Consumidores. Revista de Derecho, 17, 41-62. https://doi.org/10.4067/s0718-09502004000200002

Momberg Uribe, R. (2013a). Artículo 1 № 1 LPDC. En I. De la Maza y C. Pizarro Wilson (eds.), La protección de los derechos de los consumidores. Santiago: Thomson Reuters.

Momberg Uribe, R. (2013b). Artículo 2 LPC. En I. De la Maza y C. Pizarro Wilson (eds.), La protección de los derechos de los consumidores. Santiago: Thomson Reuters.

Momberg Uribe, R. (2013c). Artículo 2 bis LPDC. En I. De la Maza y C. Pizarro Wilson (eds.), La protección de los derechos de los consumidores. Santiago: Thomson Reuters.

Observatorio de Conflictividad Civil y Acceso a la Justicia. (2018). Conflictividad Civil y Barreras de Acceso a la Justicia en América Latina. Informe de Consumo. Santiago: CEJA.

Organización para la Cooperación y el Desarrollo Económicos (OCDE). (1999). Recomendación del Consejo de la OCDE relativa a los lineamientos para la protección al consumidor en el contexto del comercio electrónico. 9 de diciembre.

Organización para la Cooperación y el Desarrollo Económicos (OCDE). (2007). Recomendación de la OCDE sobre Resolución de Disputas y Resarcimiento a los 
Consumidores. Comité para Políticas de Consumo de la OCDE, adoptada por el Consejo de la OCDE el 12 de julio de 2007.

Organización Mundial de la Salud (OMS). (2017). Evaluación de la gravedad de influenza pandémica (PISA): guía de la OMS para evaluar la gravedad de influenza en las epidemias y las pandemias. Ginebra: Organización Mundial de la Salud.

Organización Mundial de la Salud (OMS). (2020a). Brote de enfermedad por coronavirus (COVID-19): orientaciones para el público. Recuperado de https:// www.who.int/es/emergencies/diseases/novel-coronavirus-2019/advice-for-public

Organización Mundial de la Salud (OMS). (2020b). Preguntas y respuestas sobre la enfermedad por coronavirus (COVID-19). Recuperado de https://www.who. int/es/emergencies/diseases/novel-coronavirus-2019/advice-for-public/q-acoronaviruses

Papayannis, D. (2020). Razonabilidad e incertidumbre en los estándares de diligencia. Revista de Derecho y Ciencias Sociales, 1(1), 9-38.

Parra Lucán, M. (2015). Sobre si un producto es defectuoso por los riesgos que presenta aunque no haya causado un daño y sobre si los gastos de retirada y recuperación son indemnizables. Revista CESCO de Derecho de Consumo, 13, 144-154.

Paúl Díaz, Á. (2020). Coronavirus, legislación y restricciones de derechos. Revista Chilena de Derecho, 47(1), V-VII.

Pinochet Olave, R. (2005). La formación del consentimiento a través de las nuevas tecnologías de la información. Parte II: La aceptación electrónica. iContratantes electrónicos, contratantes presentes o ausentes? Revista Ius et Praxis, 11 (1), 55-92. https://doi.org/10.4067/s0718-00122005000100004

Pinochet Olave, R. (2006). Aspectos especiales en la formación del contrato electrónico. En Cuadernos de Análisis Jurídica III. Santiago: Fundación Fernando Fueyo.

Pinochet Olave, R. (2011). Delimitación material del Derecho del Consumo: Evolución de la noción de consumidor en la doctrina nacional. En M. Vásquez Palma (ed.), Estudios de Derecho Comercial. Santiago de Chile: Abeledo Perrot.

Pizarro Wilson, C. (2008). La culpa como elemento constitutivo del incumplimiento en las obligaciones de medio o de diligencia. Revista de Derecho de la Pontificia Universidad Católica de Valparaíso, (31), 255-265. https://doi. org/10.4067/s0718-68512008000200005

Ruiz-Tagle Vial, C. (2010). Curso de Derecho Económico. Santiago: Librotecnia.

Reich, N. (1999). Mercado, Derecho y protección del consumidor. El consumidor como ciudadano. Derecho del Consumidor, 10, 3-20.

San Martín Neira, L. (2019). Desastres naturales y responsabilidad civil: posible concurso causal entre actividad humana y fenómeno natural. En M. Gómez de la Torre Vargas, G. Hernández Paulsen, F. Lathrop Gómez y M. Tapia Rodríguez (eds.), Estudios de Derecho Civil XIV. Santiago de Chile: Thomson Reuters.

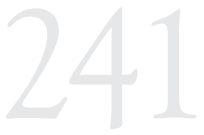

LA INOCUIDAD:

PRINCIPIO

INFORMANTEY DE ADECUACIÓN DE

DEBERES

PREVENTIVOSY

BUENAS PRÁCTICAS

EN LA ATENCIÓN

REMOTAY

PRESENCIAL DEL

CONSUMIDOR

DURANTE EL

CONTEXTO DE

LA PANDEMIA DE

COVID-19

SAFETY: PRINCIPLE

IN THE ADEQUACY

OF PREVENTIVE

DUTIES AND GOOD

PRACTICES IN

REMOTE AND FACE-

TO-FACE CONSUMER

ATTENTION DURING

THE CONTEXT OF

THE COVID-19

PANDEMIC 
San Martín Neira, L. (2020). 27F, $18^{\circ}$ y Covid-19: derecho de desastres y caso fortuito. El Mercurio Legal, 18 de marzo. Recuperado de https://www.elmercurio. com/Legal/Noticias/Opinion/2020/03/18/27F-18O-y-Covid19-derecho-dedesastres-y-caso-fortuito.aspx, revisado el 20 de julio de 2020.

Secretaría de Estado de Comercio del Ministerio de Industria, Comercio y Turismo. (2020). Guía de Buenas Prácticas para los establecimientos del sector comercial. Madrid: Ministerio de Industria, Comercio y Turismo.

Sierra H., A., \& Nasser Olea, M. (2012). La responsabilidad del empleador por enfermedades profesionales de sus trabajadores. Enfoque jurisprudencial. Revista Chilena de Derecho, 39(1), 57-76. https://doi.org/10.4067/s0718 34372012000100004

Stiglitz, G. (1997). Reglas para la defensa de los Consumidores y Usuarios. Rosario: Juris.

World Healthcare Organization (WHO). (22 de abril de 2020). Make no mistake: we have a long way to go. This virus will be with us for a long time. Recuperado de https://www.who.int/dg/speeches/detail/who-director-general-s-openingremarks-at-the-media-briefing-on-covid-19--22-april-2020

Zentner, D. (2017). La responsabilidad por productos defectuosos en el Derecho Argentino. En J. Villalba y A. Alarcón (dirs.), Escritos de Derecho Privado Contemporáneo. Contratos, responsabilidad y mercado en el siglo XXI (pp. 299-323). Bogotá: Ibañez.

\section{Jurisprudencia, normativa y otros documentos legales}

Audiencia Pública, Recurso 08-10070 (Corte de Casación, Tercera Sala de lo Civil [Francia], 1 de abril de 2009). Recuperado de https://www.legifrance.gouv. fr/affichJuriJudi.do?oldAction $=$ rechJuriJudi\&idTexte $=$ JURITEXT0000204837 $28 \&$ fastReqId $=413535063 \&$ fastPos $=1$

Circular interpretativa sobre buenas prácticas en comercio electrónico, Resolución Exenta N 184 (Sernac [Chile]). Diario Oficial, 21 de marzo de 2019.

Circular interpretativa sobre supermercados y almacenes, Resolución Exenta $\mathrm{N}^{\circ}$ 185 (Sernac [Chile]). Diario Oficial, 21 de marzo de 2019.

Circular interpretativa sobre continuidad de servicios ante eventos excepcionales, Resolución Exenta N 950 (Sernac [Chile]). Diario Oficial, 29 de noviembre de 2019.

Circular interpretativa sobre contratación a distancia durante la pandemia provocada por el Covid-19 Servicio Nacional del Consumidor, Resolución Exenta N 326 (Sernac [Chile]). Diario Oficial, 6 de abril de 2020.

Circular interpretativa sobre suspensión de plazos de las garantías legales, voluntarias y de satisfacción durante la crisis sanitaria derivada de Covid-19, Resolución Exenta No340 (Sernac [Chile]). Diario Oficial, 9 de abril de 2020. 
Circular interpretativa sobre buenas prácticas de los proveedores frente a la pandemia provocada por el Coronavirus (Covid-19), Resolución Exenta $N^{\circ} 360$ (Sernac [Chile]). Diario Oficial, 20 de abril de 2020.

Circular interpretativa sobre resguardo de la salud de los consumidores y de medidas alternativas de cumplimiento, suspensión y extinción de las prestaciones, frente a la pandemia provocada por Coronavirus (COVID-19), Resolución Exenta No 371 (Sernac [Chile]). Diario Oficial, 23 de abril de 2020.

Code Civil (Francia, 1804).

Código Civil (Chile). Diario Oficial, 14 de diciembre de 1855.

Constitución Política de la República (Chile). Diario Oficial, 22 de septiembre de 2005.

Convención sobre los Derechos del Niño (ONU, 20 de noviembre de 1989).

Convención Interamericana para la eliminación de todas las formas de discriminación contra las personas con Discapacidad, Decreto 99/MinRel/2002 que la promulga (Chile). Diario Oficial, 20 de junio de 2002.

Convención sobre los derechos de las personas con discapacidad, Decreto 201/ MinRel/2008 que la promulga junto a su protocolo facultativo (Chile). Diario Oficial, 17 de septiembre de 2008.

Decreto 104 que fija el texto refundido, coordinado y sistematizado del Título 1 de la Ley 16.282 (Chile). Diario Oficial, 25 de junio de 1977.

Decreto 830/MinRel/1990 que la promulga (Chile). Diario Oficial, 27 de septiembre de 1990.

Decreto 104 (MinInterior [Chile]). Diario Oficial, 18 de marzo de 2020.

Decreto 269 (MinInterior [Chile]). Diario Oficial, 16 de junio de 2020.

LA INOCUIDAD:

PRINCIPIO

INFORMANTEY DE

ADECUACIÓN DE

DEBERES

PREVENTIVOSY

BUENAS PRÁCTICAS

EN LA ATENCIÓN

REMOTA Y

PRESENCIAL DEL

CONSUMIDOR

DURANTE EL

CONTEXTO DE

LA PANDEMIA DE

COVID-19

SAFETY: PRINCIPLE

INTHE ADEQUACY

OF PREVENTIVE

DUTIES AND GOOD

PRACTICES IN

REMOTE AND FACE-

TO-FACE CONSUMER

ATTENTION DURING

THE CONTEXT OF

THE COVID-19

PANDEMIC

Directiva 2001/95/CE del Parlamento Europeo y del Consejo, sobre la seguridad general de los productos (Chile). Diario Oficial, 15 de enero de 2002.

Ley que establece normas sobre protección de los derechos de los consumidores, Ley N 19.496 (CNCh [Chile]). Diario Oficial, 7 de marzo de 1997.

Ley sobre Matrimonio Civil, Ley No 19.947 (CNCh [Chile]). Diario Oficial, 17 de mayo de 2004.

Ley que modifica la Ley $N^{\circ} 19.496$ sobre Protección de los Derechos de los Consumidores, Ley N 21.081 (CNCh [Chile]). Diario Oficial, 13 de septiembre de 2018.

Historia de la Ley 19.496 (Chile). Recuperado de http://www.leychile.cl/Consulta/ portada_hl?tipo_norma=XX1\&nro_ley=19496\&anio=2013 (consultado el 13 de octubre de $2 \overline{0} 20$ ).

Ley 6/2019, Estatuto de las personas consumidoras de Extremadura (España). Diario Oficial, 20 de febrero de 2019. 
Real Decreto 1801/2003 sobre seguridad general de los productos (España). Boletín Oficial del Estado, 10 de enero de 2004.

Resolución Exenta No 208 (Ministerio de Salud [Chile]). Diario Oficial, 25 de marzo de 2020.

Resolución Exenta № 215 (Ministerio de Salud [Chile]). Diario Oficial, 30 de marzo de 2020.

Resolución Exenta № 244 (Ministerio de Salud [Chile]). Diario Oficial, 7 de abril de 2020.

Resolución Exenta № 258 (Ministerio de Salud [Chile]). Diario Oficial, 15 de abril de 2020.

Resolución Exenta 282 (Ministerio de Salud [Chile]). Diario Oficial, 17 de abril de 2020.

Texto Refundido de la Ley General para la Defensa de los Consumidores y Usuarios, Real Decreto Legislativo 1/2007 (España). Boletín Oficial del Estado, 30 de noviembre de 2007.

Vergara Arias vs. Banco Santander Chile S.A. (C. Ap. de Temuco [Chile], 13 de febrero de 2017). 